Canadian

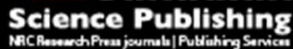

Canadian Geotechnical Journal Revue canadienne de géotechnique

\title{
Finite Element Modeling of Lateral Pipeline-Soil Interactions in Dense Sand
}

\begin{tabular}{|r|l|}
\hline Journal: & Canadian Geotechnical Journal \\
\hline Manuscript ID & cgj-2015-0171.R1 \\
\hline Manuscript Type: & Article \\
\hline Date Submitted by the Author: & 07-Aug-2015 \\
\hline Complete List of Authors: & $\begin{array}{l}\text { Roy, Kshama; Memorial University, Civil Engineering } \\
\text { Hawlader, Bipul; Memorial Unversity of Newfoundland, } \\
\text { Kenny, Shawn; Carleton University, Civil and Environmental Engineering } \\
\text { Moore, Ian; Queen's University, Civil Engineering }\end{array}$ \\
\hline Keyword: & $\begin{array}{l}\text { pipeline, lateral movement, Mohr-Coulomb model, finite element analyses, } \\
\text { dense sand }\end{array}$ \\
\hline & \\
\hline
\end{tabular}




\title{
Finite Element Modeling of Lateral Pipeline-Soil Interactions in Dense Sand
}

\author{
Kshama Roy ${ }^{1}$, Bipul Hawlader ${ }^{2 *}$, Shawn Kenny ${ }^{3}$ and Ian Moore ${ }^{4}$
}

${ }^{1} \mathrm{PhD}$ Candidate, Department of Civil Engineering, Faculty of Engineering and Applied Science, Memorial University of Newfoundland, St. John's, Newfoundland and Labrador A1B 3X5, Canada

${ }^{2}$ Corresponding Author: Associate Professor, Department of Civil Engineering, Faculty of Engineering and Applied Science, Memorial University of Newfoundland, St. John's, Newfoundland and Labrador A1B 3X5, Canada

Tel: +1 (709) 864-8945 Fax: +1 (709) 864-4042 E-mail: bipul@mun.ca

${ }^{3}$ Associate Professor, Department of Civil and Environmental Engineering, Faculty of Engineering and Design, Carleton University, 1125 Colonel By Drive, Ottawa, ON, K1S 5B6, Canada

${ }^{4}$ Professor and Canada Research Chair in Infrastructure Engineering, GeoEngineering Centre at Queen's - RMC, Queen's University, Kingston, ON, K7L 4V1, Canada

Number of Figures: 19

Number of table: 1

KEYWORDS: pipeline, Mohr-Coulomb model, finite element analyses, dense sand, lateral movement 


\begin{abstract}
:
Finite element (FE) analyses of pipeline-soil interaction for pipelines buried in dense sand subjected to lateral ground displacements are presented in this paper. Analysis is performed using the Arbitrary Lagrangian-Eulerian (ALE) method available in Abaqus/Explicit FE software. The pipeline-soil interaction analysis is performed in the plane strain condition using the Mohr-Coulomb (MC) and a modified Mohr-Coulomb (MMC) models. The MMC model considers a number of important features of stress-strain and volume change behaviour of dense sand including the nonlinear pre- and post-peak behaviour with a smooth transition and the variation of the angle of internal friction and dilation angle with plastic shear strain, loading conditions (triaxial or plane strain), density and mean effective stress. Comparing FE and experimental results, it is shown that the MMC model can better simulate the force-displacement response for a wide range of lateral displacements of the pipe for different burial depths, although the peak force on the pipe could be matched using the MC model. Examining the progressive development of zones of large inelastic shear deformation (shear bands), it is shown that the mobilized angle of internal friction and dilation angle vary along the length of the shear band, however constant values are used in the MC model. A comprehensive parametric study is also performed to investigate the effects of pipeline diameter, burial depth and soil properties. Many important aspects in the force-displacement curves and failure mechanisms are explained using the present FE analyses.
\end{abstract}

Keywords: pipeline, lateral movement, Mohr-Coulomb model, finite element analyses, dense sand 


\section{Introduction}

Pipelines are extensively used for transporting water and hydrocarbons. Any relative displacements (e.g. during slope movement) between pipeline and soil exert forces on pipelines. The pipeline-soil interaction analyses are generally performed defining the force-displacement curves in the lateral, vertical and axial directions based on available guidelines (American Lifelines Alliance 2005; Honegger and Nymann 2004). Pipelines can be buried in a wide variety of soils and subjected to loading from different directions. Pipelines buried in dense sand subjected to large lateral displacement are the focus of the present study, since nonuniform lateral displacement leads to longitudinal bending and other structural demands that can exceed the structural capacity. Experimental studies have been conducted in the past to understand lateral pipeline-soil interaction in sand (e.g. Audibert and Nyman 1977; Trautmann 1983; Scarpelli et al. 1999; Turner 2004; Wijewickreme et al. 2009; Daiyan 2013; Almahakeri et al. 2013, 2014). From the test results, the force-displacement curves could be obtained and the failure mechanisms could be interpreted. The displacements of soil particles with lateral movement of the pipe could be visualized using the advanced particle image velocimetry (PIV) techniques (Burnett 2015). Guo and Stolle (2005) compiled the data from experimental studies and showed a wide variation in the non-dimensional peak force, which depends upon sand properties, diameter of the pipe, burial depth, and test procedure. In addition to the peak force, the shape of the force-displacement curve is also influenced by these factors. In structural modeling, the force-displacement curves as elastoplastic soil springs are given as input, which is valid up to mobilization of the peak force. However, a section of pipeline might experience large displacements where post-peak soil resistance governs the response. Recognizing this, design guidelines (e.g. DNV 2007) suggested that the post-peak response of dense sand should be 
considered in uplift resistance calculation as the sand moves to a looser state at displacements beyond the peak displacement. As shown later, the mobilization of angles of internal friction $\left(\phi^{\prime}\right)$ and dilation $(\psi)$ both in pre- and post-peak levels is equally important for calculation of lateral resistance. Moreover, a better representation of force-displacement curves up to sufficiently large displacements will improve structural modeling of pipeline.

Continuum finite element (FE) analyses have been performed in the past to simulate lateral pipeline--soil interaction in sand (e.g. Yimsiri et al. 2004; Guo and Stolle 2005; Xie 2008; Daiyan et al. 2011; Jung et al. 2013). The soil constitutive model used in the analysis influences FE simulation results (Yimsiri et al. 2004). Figure 1 shows the typical stress-strain and volume change behaviour of dense sand in consolidated isotropically drained (CID) triaxial compression tests. The stress ratio $\left(q / p^{\prime}\right)$, (where $p^{\prime}$ is the mean effective stress and $q$ is deviatoric stress) increases gradually (hardening) up to the peak and then decreases (softening) to the critical state at large axial strains (Fig. 1a). The axial strain at the peak stress ratio $\left(\varepsilon_{a}^{p}\right)$ decreases with confining pressure $\left(\sigma_{c}\right)$. Experimental evidence also shows that $\varepsilon_{a}^{p}$ decreases with relative density (Lee 1965; Kolymbas and Wu 1990; Lancelot et al. 2006). Figure 1(b) shows higher dilation in tests with low $\sigma_{\mathrm{c}}$. Moreover, the volumetric expansion starts at lower axial strains for low confining pressures. These characteristics observed not only in the triaxial stress condition; the results from direct shear tests also show similar behaviour for different vertical normal stresses (Lings and Dietz 2004).

Another important experimental observation is that the behaviour of dense sand in triaxial and simple shear conditions is different. For example, Ahmed (1973) conducted tests on crushed silica sand in drained triaxial (TX) and plane strain (PS) loading conditions. The peak friction angles $\left(\phi_{p}^{\prime}\right)$ from his test results are shown in Fig. 2. Three key features of these test results need 
to be mentioned: (i) $\phi_{p}^{\prime}$ for the plane strain condition $\left(\phi_{p}^{\prime P S}\right)$ is higher than $\phi_{p}^{\prime}$ for the triaxial condition $\left(\phi_{p}^{\prime T X}\right)$, and the value of $\phi_{p}^{\prime P S}-\phi_{p}^{\prime T X}$ is higher at low stress levels, (ii) both $\phi_{p}^{\prime P S}$ and $\phi_{p}^{\prime T X}$ increase with $D_{r}$, and (iii) $\phi_{p}^{\prime}$ for both TX and PS configurations decrease with of confining pressure.

In summary, pre-peak hardening, post-peak softening, density and confining pressure dependent $\varepsilon_{a}^{p}$, angle of internal friction and dilation angle are the common features of the stressstrain behaviour of dense sand. The mode of shearing (TX or PS) also significantly influences the behaviour. All these features of the stress-strain behaviour of dense sand have not been considered in the available FE modeling of pipeline-soil interaction. For example, Yimsiri et al. (2004) used the Mohr-Coulomb model with constant angles of internal friction and dilation (MC). They also conducted FE analyses using the Nor-Sand soil constitutive models. Guo and Stolle (2005) and Daiyan et al. (2011) considered the effects of $p^{\prime}$ and plastic shear strain on $\phi^{\prime}$ and $\psi$ but did not incorporate the effects of density on the plastic strain required to mobilize the peak value. Robert (2010) and Jung et al. (2013) incorporated the post-peak softening using a linear variation of angles of internal friction and dilation with plastic strain, but did not consider the pre-peak hardening. However, Jung et al. (2013) conducted the simulation using plane strain strength parameters.

From a numerical point of view, the softening of soil causes strain localization into shear bands resulting in significant mesh distortion in typical FE formulations expressed in the Lagrangian framework (Qiu et al. 2009; Pike et al. 2013). It is preferable to avoid such mesh distortion issues in FE simulation. The distinct element method has also been used in the past to 
accommodate large soil movement around the pipe and to continue the analysis up to large pipe displacements (Yimsiri and Soga 2006).

The main objective of the present study is to simulate lateral pipeline-soil interaction using Abaqus/Explicit (taking the advantages of better modeling capability of strength degradation in shear bands over Abaqus/Standard) implementing a modified Mohr-Coulomb (MMC) model that can capture the features of dense sand behaviour discussed above. The paper has been organized in the following way. First, the development of the MMC model is presented. The key model parameters and their relations to experimental results are discussed. Second, the FE simulations of triaxial test results are performed to show the performance of the proposed MMC model. Third, the FE simulations are performed for lateral pipeline-soil interaction and compared with test results. Finally, a comprehensive parametric study is performed.

\section{Modeling of Soil Behaviour}

The elastic perfectly plastic Mohr-Coulomb (MC) model, in its original form and also after some modifications, has been used by a number of researchers in the past for pipeline-soil interaction analysis (e.g. Moore and Booker 1987; Taleb and Moore 1999; Ellis and Springman 2001; Yimsiri et al. 2004; Guo and Stolle 2005; Daiyan et al. 2011; Almahakeri et al. 2012; Kouretzis et al. 2013). In MC model, the soil behaviour is elastic until the stress state reaches the yield surface which is defined by the Mohr-Coulomb failure criterion. This model is available in commercial software packages including Abaqus FE program. The modification of MC model has been performed by implementing some additional features of dense sand behaviour (Guo and Stolle 2005; Daiyan et al. 2011; Jung et al. 2013). The present FE analyses are performed using a 
MMC model incorporating all of the features of dense sand behaviour discussed in the following sections.

a) Angle of internal friction in triaxial compression (TX) and plane strain (PS) conditions

The strength of sand is characterized by mobilized angle of internal friction $\left(\phi^{\prime}\right)$ and dilation angle $(\psi)$. First, two limiting values of $\phi^{\prime}$ are examined: (i) at the peak $\left(\phi_{p}^{\prime}\right)$ and (ii) the critical state $\left(\phi^{\prime}{ }_{c}\right)$.

Experimental results show that $\phi_{p}^{\prime}$ depends on density of sand and also on the direction of shearing (e.g. Bolton 1986; Houlsby 1991; Schanz and Vermeer 1996). Kulhawy and Mayne (1990) compiled a large volume of test data and showed that, for dense sand, $\phi_{p}^{\prime P S}$ is approximately 10 to $20 \%$ higher than $\phi_{p}^{\prime T X}$. Furthermore, experimental evidence also shows that $\phi_{p}^{\prime}$ decreases with confining pressure $\left(\sigma_{\mathrm{c}}\right)$ (Fig. 1) or $p^{\prime}$ at failure (Bolton 1986).

Assuming unique $\phi_{c}^{\prime}$ for both TX and PS conditions, Bolton (1986) proposed the following relationships from test results for 17 sands.

[1] $\phi_{p}^{\prime}-\phi_{c}^{\prime}=A_{\psi} I_{R}$

where $A_{\psi}=3$ for TX and 5 for PS conditions. $I_{R}$ is the relative density index defined as $I_{R}=I_{D}\left(Q-\ln p^{\prime}\right)-R$ in which $I_{D}=$ relative density $\left(=D_{r}(\%) / 100\right), Q=10$ and $R=1$. Bolton (1986) also recognized that stress and strain non-uniformity could be strong at very low $p^{\prime}$. Moreover, at that time, accurate measurement of small stresses and strains was difficult. As such Bolton (1986) set the maximum limit of $I_{R}=4$. White et al. (2008) also used $I_{R}=0-4$ as a permissible range for modeling pipelines buried in sand. Therefore, according to Eq. (1), the maximum value of $\phi_{p}^{\prime}-\phi_{c}^{\prime}$ of $12^{\circ}$ and $20^{\circ}$ for the TX and PS conditions, respectively, are used in the present study. 
Equation (1) has been verified with additional test data and used by many researchers. For example, Houlsby (1991) developed a relationship similar to Eq. (1) based on the critical state theory. Similarly, based on Eq. (1), Schanz and Vermeer (1996) showed that $\phi_{p}^{\prime P S}=\left(5 \phi_{p}^{\prime T X}-2 \phi_{c}^{\prime}\right) / 3$ is valid for a wide range of test results on Hostun dense sand. In other words, for dense sand at low stress levels, $\phi_{p}^{\prime P S}$ is higher than ${\phi^{\prime}}_{p}^{T X}$. Attempts have also been made in the past to develop relationships between $\phi^{\prime P S}$ and $\phi^{\prime}$ obtained from direct shear tests $\left(\phi^{\prime D S}\right)$ (Taylor 1948; Davis 1968; Rowe 1969). Lings and Dietz (2004) provided a detailed discussion of these relationships. From comparisons with test results, they showed that $\phi_{p}^{\prime P S} \approx$ $\phi_{p}^{\prime D S}+5^{\circ}$, where ${\phi^{\prime}}_{p}^{D S}$ is the peak friction angle from a direct shear test. In summary, although triaxial and direct shear tests are widely used to determine $\phi^{\prime}$, it should be properly adjusted if the analysis is performed for plane strain conditions where $\phi^{\prime P S}$ is required.

The value of $A_{\psi}$ in Eq. (1) might vary with type of sand and fine contents. For example, Chakraborty and Salgado (2010) found $A_{\psi}=3.8$ for Toyoura sand for both TX and PS conditions, while Xiao et al. (2014) showed $A_{\psi}=3.0-5.53$ for Ottawa sand with $0-20 \%$ fine contents for the triaxial condition. Xiao et al. (2014) also proposed an empirical relationship for $A_{\psi}$ as a function of fine content. Moreover, $Q$ is also varied using an empirical function of $\sigma_{\mathrm{c}}$ (Chakraborty and Salgado 2010; Xiao et al. 2014), instead of a constant value as proposed by Bolton (1986). Although these empirical functions of $A_{\psi}$ and $Q$ might fit the test results better, a constant value of $Q(=10)$ and $A_{\psi}=5$ with the limiting maximum value of $\phi_{p}^{\prime}-\phi_{c}^{\prime}$ of $12^{\circ}$ and $20^{\circ}$ for $\mathrm{TX}$ and PS configurations, respectively, are used in the present study. 
Experimental evidence shows that $\phi_{c}^{\prime P S}$ is a few degrees higher than $\phi_{c}^{\prime T X}$. Bishop (1961) and Cornforth (1964) conducted laboratory tests over the full range of relative densities at a wide range of $\sigma_{c}$ and showed that ${\phi_{c}^{\prime}}^{P S}$ is approximately $4^{\circ}$ greater than ${\phi^{\prime}}_{c}^{T X}$. A similar trend was found from laboratory tests on Toyoura sand, and it has been shown that $\phi_{c}^{\prime P S} \approx 34.5^{\circ}-38^{\circ}$ while ${\phi_{c}^{\prime}}_{c}^{T X} \approx 33^{\circ}$ (Tatsuoka et al. 1986; Pradhan et al. 1988; Yoshimine 2005).

In this study, $\phi_{c}^{\prime T X}=31^{\circ}{\phi_{c}^{\prime}}_{c}^{P S}=35^{\circ}$ are used. The authors also aware of the fact that $\phi_{c}^{\prime}$ might slightly increase with decrease in $p^{\prime}$ (Lings and Dietz 2004); however, such variation is not considered in this study.

Bolton (1986) also showed that the maximum dilation angle $\left(\psi_{p}\right)$ is related to the peak and critical state friction angle as:

[2] $\quad \phi_{p}^{\prime}-\phi_{c}^{\prime}=k_{\psi} \psi_{p}$

where $k_{\psi}=0.8$ for PS and 0.5 for TX configurations (Bolton 1906). Note that $k_{\psi}$ might be also dependent on type of sand, fines content and/or gravel fraction (Simoni and Houlsby 2006; Chakraborty and Salgado 2010; Xiao et al. 2014).

\section{b) Stress-strain behaviour of dense sand}

Generally in the widely used MC model it is assumed that: (i) plastic strains develop only when the stress state is on the failure (yield) surface, (ii) any change in stresses inside the yield surface results in only elastic strain, and (iii) soil deforms at a constant dilation angle once the stress state reaches the yield surface. However, experimental evidence shows that plastic strains usually develop well before failure. In order to capture this behaviour, constitutive models of different forms have been proposed in the past (Prevost 1985; Gajo and Wood 1999; Dafalias 
and Manzari 2004). Similar to these works, it is assumed that the plastic deformation occurs only for changes of $q / p^{\prime}$. The development of plastic strain for loading under constant stress ratio is neglected because the soil considered in this study is not loose and crushing of sand grains is not expected because of stress increase due to displacement of the pipeline.

Following the conceptual frameworks developed in previous studies (e.g. Jardine 1992; Mitchell and Soga 2005), the stress-strain behaviour of dense sand is divided into three zones as shown in Fig. 3.

Zone-I: In this zone, elastic (linear and/or nonlinear) deformation occurs. In the pure linear elastic zone the soil particles do not slide relative to each other. However, in nonlinear elastic deformation small slide or rolling between particles might occur but the deformation is recoverable during unloading. The deformation behaviour in this zone can be defined by elastic properties namely Young's modulus $(E)$, and Poisson's ratio (v).

Zone-II: If the shearing is continued, the soil element will move to zone-II (Fig. 3) which can be considered as the "pre-peak plastic zone" (Mitchell and Soga 2005). The mobilized $\phi^{\prime}$ (Fig. 3) is used to define the yield surface using the Mohr-Coulomb model. When the stress state approaches the initial yield surface (i.e. yield surface with $\phi^{\prime}$ in at point A in Fig. 3), plastic strains occur upon further loading. The initial yield surface of dense sand is inside the failure envelope defined by the peak friction angle. The pre-peak plastic deformation of geomaterials has been recognized by many researchers from experimental data, and multiple yield surfaces are used to simulate this; for example, the multi-yield surface model (Mroz 1967), the nested surface plasticity model (e.g. Prévost 1985), the bounding surface plasticity model (Dafalias and Herrman 1982), and the subloading surface model (Hashiguchi and Ueno 1977). These complex models can simulate many important features including the stress-strain behaviour during cyclic 
loading. However, in the present MMC model the mobilized $\phi^{\prime}$ and $\psi$ are varied with accumulated engineering plastic shear strain $\left(\gamma^{p}\right)$ as shown in Fig. 3. A set of equations (Eq. 3-8) are proposed to model this behaviour after some modifications of similar type of models proposed in previous studies (Vermeer and de Borst 1984; Tatsuoka et al. 1993; Hsu and Liao 1998).

In the pre-peak zone-II, $\phi^{\prime}$ and $\psi$ increase from $\phi_{\text {in }}^{\prime}$ and $\psi_{\text {in }}$ to the peak values $\phi_{p}^{\prime}$ and $\psi_{\mathrm{p}}$ at strain $\gamma_{p}^{p}$. Based on Rowe (1969), Mitchell and Soga (2005) suggested that the mobilized $\phi^{\prime}$ of sand is the sum of the contributions of four components: interparticle friction, rearrangement of particles (fabric), crushing, and dilation. As $p^{\prime}$ is not very high in the pipeline-soil interaction analysis being undertaken here, the crushing effect is negligible. At the beginning of plastic deformation $\psi_{i n}=0$ is assumed. Therefore, interparticle friction and soil fabric are the main contributors to $\phi_{i n}^{\prime}$ (point A in Fig. 4). Based on typical contributions of each component of $\phi^{\prime}$ (Mitchell and Soga, 2005), $\phi_{i n}^{\prime}=29^{\circ}$ is assumed in this study.

For given relative density and confining pressure, $I_{R}$ can be calculated, which can be then used to calculate $\phi_{p}^{\prime}$ using Eq. (1). Now using Eq. (2), the value of $\psi_{p}$ can be calculated. However, as discussed in the introduction, the shear strain or displacement required to mobilize $\phi_{p}^{\prime}$ decreases with density and increases with confining pressure (Lee et al. 1965; Tatsuoka et al. 1986; Hsu and Liao 1998; Lings and Dietz 2004). The effects of density and stress level are incorporated in $\gamma_{p}^{p}$ as:

[3] $\quad \gamma_{p}^{p}=\gamma_{c}^{p}\left(p^{\prime} / p_{a}^{\prime}\right)^{m}$

[4] $\gamma_{c}^{p}=C_{1}-C_{2} I_{D}$ 
where $\gamma_{c}^{p}=$ strain softening parameter; $p_{a}^{\prime}=$ reference pressure which is considered as the atmospheric pressure $(=100 \mathrm{kPa}) ; m, C_{1}$ and $C_{2}$ are soil parameters, which could be obtained from a set of triaxial or simple shear tests at different confining pressures and densities. Further explanation of these parameters are provided in the following sections.

The following sine functions are then used to model the variation of mobilized $\phi^{\prime}$ and $\psi$ in zone-II.

$$
\begin{aligned}
& \phi^{\prime}=\phi_{i n}^{\prime}+\sin ^{-1}\left[\left(\frac{2 \sqrt{\gamma^{p} \gamma_{p}^{p}}}{\gamma^{p}+\gamma_{p}^{p}}\right) \sin \left(\phi_{p}^{\prime}-\phi_{i n}^{\prime}\right)\right] \\
& \psi=\sin ^{-1}\left[\left(\frac{2 \sqrt{\gamma^{p} \gamma_{p}^{p}}}{\gamma^{p}+\gamma_{p}^{p}}\right) \sin \left(\psi_{p}\right)\right]
\end{aligned}
$$

The lines $\mathrm{AB}$ and DE in Fig. 3 demonstrate the variation of $\phi^{\prime}$ and $\psi$, respectively, in the prepeak zone for $D_{r}=80 \%$ and $p^{\prime}=40 \mathrm{kPa}$.

\section{Zone-III:}

If the shearing is continued, both $\phi^{\prime}$ and $\psi$ will decrease with $\gamma^{\mathrm{p}}$ in Zone-III (Fig. 3). This zone is referred as the "post-peak softening zone." The following exponential functions are used to define the curves $B C$ and $E F$ to model the variation of $\phi^{\prime}$ and $\psi$ with plastic strain, respectively.

[8] $\psi=\psi_{p} \exp \left[-\left(\frac{\gamma^{p}-\gamma_{p}^{p}}{\gamma_{c}^{p}}\right)^{2}\right] \quad$ curve $E F$ 
The strain softening parameter $\gamma_{c}^{p}$ controls the shape of the post-peak curves. The lower the value of $\gamma_{c}^{p}$, the faster the decrease of $\phi^{\prime}$ from $\phi_{p}^{\prime}$ to $\phi_{c}^{\prime}$. After some algebraic calculation, it can be shown from Eqs. (7) and (8) that the point of inflection of the post-peak softening curve occurs at $\gamma_{c}^{p} / \sqrt{2}$ from $\gamma_{p}^{p}$ as shown by the open circles in Fig. 3. The shapes of the curves defined by Eqs. (6-8) are very similar to the observed behaviour of dense sand.

The novel aspects that the present MMC model adds to the existing models of similar type for pipeline-soil interaction analysis (e.g. Guo and Stolle 2005; Robert 2010; Daiyan et al. 2011; Jung et al. 2013a,b; Pike et al. 2013) are primarily twofold. Firstly, nonlinear pre- and post-yield behaviour with a smooth transition is incorporated. Secondly, the mobilization of $\phi^{\prime}$ and $\psi$ with plastic strain, including the peak values, depends on density and mean effective stress.

c) Elastic properties

Poisson's ratio $(v)$ and Young's modulus $(E)$ of the soil are the two elastic parameters. The Poisson's ratio of 0.2 is used, which has been considered as the best representative value for dense sand (Jefferies and Been 2006). $E$ is varied with $p^{\prime}$ using the following power function (Hardin and Black 1966; Janbu 1963).

[9] $\quad E=K p_{a}\left(\frac{p^{\prime}}{p_{a}}\right)^{n}$

where $K$ is a material constant, $P_{a}$ is the atmospheric pressure $(=100 \mathrm{kPa})$ and $n$ is an exponent. A number of authors used Eq. (9) in FE modeling of pipeline-soil interaction (Taleb and Moore 1999; Yimsiri et al. 2004; Guo and Stolle 2005; Daiyan et al. 2011; Jung et al. 2013). Further discussion on the selection of elastic parameters can be found in those studies and is not repeated here. 


\section{FE Modeling of Pipeline-Soil Interaction}

Two-dimensional pipeline-soil interaction analyses are conducted using the Abaqus/Explicit FE software. The main advantages of using Abaqus/Explicit over Abaqus/Standard is that the pipe can be moved relatively large distances while still largely avoiding numerical issues associated with mesh distortion as encountered when employing Abaqus/Standard, especially in the zones of shear strain localization. Therefore, the large strains that concentrate in the shear bands can be better simulated using Abaqus/Explicit.

A typical FE mesh for $300 \mathrm{~mm}$ outer pipe diameter $(D)$ is shown in Fig. 4. For FE modeling of soil, the 4-node bilinear plane strain quadrilateral element (CPE4R) is used. The pipe is modeled as a rigid body. Abaqus/cae is used to generate the FE mesh. The structured mesh (Fig 4) is generated by zoning the soil domain. A denser mesh is used near the pipe. The bottom of the FE domain is restrained from any movements, while all the vertical faces are restrained from any lateral movement using roller supports (Fig. 4). No displacement boundary condition is applied on the top face. The pipe is placed at the desired location (i.e. wished-in-place configuration). The depth of the pipe is measured in terms of $H / D$ ratio, where $H$ is the depth from the top of the soil to the centre of the pipe. The locations of the bottom and right boundaries with respect to the location of the pipe are sufficiently large and therefore boundary effects on calculated lateral resistance, displacement and soil failure mechanisms are not found. This has been verified by a number of FE analyses setting these boundaries at larger distances than those shown in Fig. 4. The pipe is pulled laterally, without any rotation, applying a displacement boundary condition at the reference point (the center of the pipe). No additional boundary condition is applied in the vertical direction, and the pipe is free to displace in the vertical 
direction during lateral movement. The horizontal component of the reaction force at the reference point of the rigid pipe gives the lateral resistance.

The interface between pipe and soil is simulated using the contact surface approach available in Abaqus/Explicit. The Coulomb friction model is used for the frictional interface between the outer surface of the pipe and sand. In this method, the friction coefficient $(\mu)$ is defined as $\mu=\tan \left(\phi_{\mu}\right)$, where $\phi_{\mu}$ is the friction angle of the pipe-soil interface. The value of $\phi_{\mu}$ depends on the interface characteristics and relative movement between the pipe and soil. The larger values of $\phi_{\mu}$ represent the characteristics of rough uncoated pipes with rusty or corroded surfaces, while the lower values would correspond to pipes with smooth coating. The value of $\phi_{\mu}$ lies between 50 and $100 \%$ of the peak friction angle (Yimsiri et al, 2004). A value of $\mu$ equal to 0.32 is used in this study.

The numerical analysis is conducted in two steps. In the first step, geostatic stress is applied under $K_{0}=1$ condition. The value of $K_{0}$ might be smaller than 1 ; however, a parametric study shows that $K_{0}$ does not have significant effects on lateral resistance (Jung et al. 2013). In the second step, the pipe is displaced in the lateral direction specifying a displacement boundary condition at the reference point of the pipe.

Abaqus does not have any direct option for modeling stress-strain behaviour using the proposed MMC model; therefore, in this study it is implemented by developing a user subroutine VUSDFLD written in FORTRAN. The stress and strain components are called in the subroutine in each time increment. From the stress components, $p^{\prime}$ is calculated. The strain components are transferred to the principal strain components and stored as state variables. The plastic strain increment $\left(\Delta \gamma^{p}\right)$ in each time increment is calculated as $\Delta \gamma^{p}=\left(\Delta \varepsilon_{1}^{p}-\Delta \varepsilon_{3}^{p}\right)$, where $\Delta \varepsilon_{1}^{p}$ and $\Delta \varepsilon_{3}^{p}$ are the major and minor principal plastic strain components, respectively. The value of $\gamma^{p}$ is 
calculated as the sum of incremental $\Delta \gamma^{p}$ over the period of analysis. In the subroutine, $\gamma^{p}$ and $p^{\prime}$ are defined as two field variables FV1 and FV2, respectively. In the input file, using Eqs. (1-8), the mobilized $\phi^{\prime}$ and $\psi$ are defined in tabular form as a function of $\gamma^{p}$ and $p^{\prime}$. During the analysis, the program accesses the subroutine and updates the values of $\phi^{\prime}$ and $\psi$ with field variables.

Two sets of FE analyses in the plane strain condition are performed for lateral displacement of the pipe. In the first set, analyses are performed for $D=102 \mathrm{~mm}$ pipes and compared with Trautmann (1983) model test results, which is denoted the "model test simulation." In the second set, a parametric study is performed varying pipe diameter, burial depth and soil properties. In addition, triaxial test results are simulated for soil parameter estimation and also to examine the performance of the proposed MMC model.

\section{FE simulation of triaxial test}

Trautmann (1983) conducted a series of model tests to understand the mechanisms involved in lateral displacement of pipes buried in sand. The tests in dry dense sand are simulated in the present study. Cornell filter sand was used in these tests. These test results have been used by previous researchers to validate the performance of numerical modeling. For example, Yimsiri et al. (2004) simulated these tests using the MC and Nor-Sand models. For the Mohr-Coulomb model, they obtained the values of $\phi^{\prime}$ and $\psi$ from direct shear test results, assuming that the plane strain nature of pipeline-soil interaction problem is more consistent with direct shear than triaxial compression. However, $\phi_{p}^{\prime}$ in PS could be approximately $5^{\circ}$ higher than $\phi_{p}^{\prime}$ in the direct shear condition (Pradhan et al. 1998; Lings and Dietz 2004). Yimsiri et al. (2004) also estimated the Nor-Sand model parameters by fitting FE simulation against the triaxial test results for Cornell filter sand (Turner and Kulhawy 1987). 
To show the performance of the proposed MMC model, consider the same triaxial test on dense sand used by Yimsiri et al. (2004). Figure 5 shows the comparison between test results and FE simulations using three models: MC, Nor-Sand, and MMC. A CAX4 element in Abaqus is used in the FE modeling. The Young's modulus is calculated using Eq. (9) substituting $p^{\prime}$ for confining pressure. As estimated by Yimsiri et al. (2004) for dense Cornell filter sand, constant $\phi^{\prime}\left(=44^{\circ}\right)$ and $\psi\left(=16^{\circ}\right)$ are used in the MC model. The FE simulation with Nor-Sand model is plotted from Yimsiri et al. (2004). The FE analysis with the present MMC model is performed using the VUSDFLD subroutine, as discussed in previous section, with triaxial condition in Eqs. (1) and (2). All other parameters used in the analysis are listed in Table 1.

Figure 5(a) shows that for the MC model $q / p^{\prime}$ increases with $\varepsilon_{a}$ to the peak value and then remains constant because a constant $\phi^{\prime}$ is used in the analysis. Figure 5(b) shows that volumetric compression occurs initially and then the soil dilates linearly, because a constant $\psi$ is used. In other words, the constant strength and dilatancy criteria take over the stress-strain behaviour once it reaches the maximum stress ratio. As stated by Wood (2007), the MC model is sufficient if the failure is the only concern; however, its ability to match the complete mechanical response of a soil element is poor. Both strength and deformation behaviour of soil are equally important in the pipeline-soil interaction analysis. Therefore, an advanced model that considers the variation of strength of dense sand with shear deformation could give improved simulation results.

Unlike the simulation with the MC model, the shape of $q / p^{\prime}-\varepsilon_{\mathrm{a}}$ and $\varepsilon_{\mathrm{v}}-\varepsilon_{\mathrm{a}}$ curves using the Nor-Sand model is very similar to test results (Fig. 5). However, a complex VUMAT subroutine needs to be developed for the Nor-Sand model while the MMC can be implemented through a relatively simple user subroutine VUSDFLD as discussed above. As shown later, most of the 
features involved in pipeline-soil interaction could be simulated using the proposed MMC model. In addition, the pre-peak hardening behaviour is considered in the present MMC model.

The simulations with the MMC model are performed for two sets of $A_{\psi}$ and $k_{\psi}$ values in Eqs. 1 and 2, respectively. First, $A_{\psi}=3$ and $k_{\psi}=0.5$ (Bolton 1986) is used. Chakraborty and Salgado (2010) showed that $A_{\psi}=3.8$ and $k_{\psi}=0.6$ match better the triaxial test results on Toyoura sand at low stresses. Therefore, FE simulation is performed also with $A_{\psi}=3.8$ and $k_{\psi}=0.6$ to show their effects. As shown in Fig. 5(a), the proposed MMC model can successfully simulate the stressstrain behaviour. Calculated $q / p^{\prime}$ nonlinearly increases with $\varepsilon_{a}$, reaches the peak, and then decreases in the post-peak region. Volumetric compression occurs initially and then the specimen expands nonlinearly with $\varepsilon_{a}$ (Fig. 5b). At large $\varepsilon_{a}, \Delta \varepsilon_{v} / \Delta \varepsilon_{a}=0$, which is different from the simulation with the MC model that calculates constant $\Delta \varepsilon_{v} / \Delta \varepsilon_{a}$ when the soil element is at the plastic state. As shown Fig. 5, the simulated results with the MMC model match well with the test results not only the peak (like the $\mathrm{MC}$ model) but also for a wide range of strains encountered in the pipeline-soil interaction analysis as presented in the following sections. It can be also concluded that the parameters listed in Table 1 can simulate the stress-strain behaviour of this sand. Adjustments to the values of $A_{\psi}$ and $k_{\psi}$ could improve matching between FE simulations and test results; however, that is not the aim of the present study.

The effects of $\sigma_{c}$ and $D_{r}$ on stress-strain behaviour are also investigated. Figure 6(a) shows the variation of $q / p^{\prime}$ with $\varepsilon_{a}$ for 4 different confining pressures $\left(\sigma_{\mathrm{c}}=20,40,80\right.$ and $\left.120 \mathrm{kPa}\right)$ for $D_{r}=80 \%$. The maximum stress ratio $\left(q / p^{\prime}\right)_{\max }$ decreases with $\sigma_{\mathrm{c}}$ because dilation is suppressed by confining pressure. The magnitude of $\varepsilon_{a}$ at $\left(q / p^{\prime}\right)_{\max }$ increases with $\sigma_{\mathrm{c}}$. Under lower confining pressures, the post-peak degradation of $q / p^{\prime}$ occurs quickly. Figure 6(b) shows that the magnitude and rate of development of $\varepsilon_{v}$ depend on confining pressure. The soil specimens compress 
initially (i.e. positive $\varepsilon_{v}$ ) and then dilate after reaching the maximum $\varepsilon_{v}$. For lower $\sigma_{c}$, dilation starts at smaller value of $\varepsilon_{a}$. Moreover, the rate of dilation and maximum volumetric expansion decrease with $\sigma_{\mathrm{c}}$. The variations of $q / p^{\prime}$ and $\varepsilon_{v}$ obtained from FE simulations using the proposed MMC model (Figs. 6a and 6b) are very similar to typical triaxial test results on dense sand as shown in Fig. 1(a) and 1(b).

Figure 7 shows the results of FE simulations for 4 relative densities $\left(D_{r}=70 \%, 80 \%, 90 \%\right.$ and $100 \%)$ under the same $\sigma_{\mathrm{c}}(=40 \mathrm{kPa})$. Figure $7(\mathrm{a})$ shows that $\left(q / p^{\prime}\right)_{\max }$ increases and $\varepsilon_{a}$ at $\left(q / p^{\prime}\right)_{\max }$ decreases with $D_{r}$. As expected, higher dilation is calculated for higher relative densities. Similar effects of $D_{r}$ on stress-strain behaviour were obtained in laboratory tests reported by previous researchers (e.g. Lee 1965).

It is also noted here that simulations of drained triaxial tests with the MMC model give a nonlinear critical state line in $e-\ln p^{\prime}$ space.

In summary, the above simulations show that the proposed MMC model can successfully simulate both pre- and post-peak behaviour of dense sand including the effects of confining pressure and relative density. This model is primarily used for pipeline-soil interaction analyses presented in the following sections, although some analyses with the MC model are performed for comparison.

\section{Model test simulation results}

Figure 8 shows the variation of dimensionless lateral force $N_{h}(=F / \gamma H D)$ with dimensionless lateral displacement $u / D$ for two burial depths $(H / D=1.5$ and 5.5). Here $F$ is the lateral force on the pipe per metre length, $H$ is the depth of the centre of the pipe, $\gamma$ is the unit weight of sand and $u$ is the lateral displacement. The peak value of $N_{h}$ is defined as $N_{h p}$ and the lateral displacement required to mobilize $N_{h p}$ is defined as $u_{p}$. Analyses are performed for the plane strain condition 
$\left(A_{\psi}=5\right.$ and $k_{\psi}=0.8$ in Eq. 1 and 2, respectively) using the user subroutine VUSDFLD. Using the initial mean effective stress at the centre of the pipe the Young's modulus $(E)$ is calculated from Eq. (9), which implies that $E$ increases with $D_{r}$ and $H$. The results of two model tests of similar conditions (Test-22 and 24) from Trautmann (1983) are also plotted in this figure. The forcedisplacement curves obtained from the FE analysis with the MMC model match very well for a wide range of lateral displacements. For $H / D=1.5$, the dimensionless force reaches the peak and then remains almost constant. However, for $H / D=5.5$, the dimensionless force reaches the peak and then decreases with further lateral displacement. The model tests conducted by Audibert and Nyman (1977) using a $25 \mathrm{~mm}$ diameter pipe buried in dense Carver sand also show similar response - no post-peak degradation of $N_{h}$ for shallow depths $(H=1.5 D$ and $3.5 D)$ but significant post-peak degradation for deep burial conditions $(H=6.5 \mathrm{D}$ and $12.5 \mathrm{D})$.

The difference between the shape of the force-displacement curves could be explained further using mobilized $\phi^{\prime}$ and $\psi$ along the shear bands and their formation. The role of $\phi^{\prime}$ is easily understood - the higher the $\phi^{\prime}$ the higher the force, provided all other conditions remain same. Figure 9 (a) shows $\gamma^{\mathrm{p}}$ at $u / D=0.12$ (i.e. after the peak) for simulation with the MMC model. The solid lines through the highly concentrated $\gamma^{\mathrm{p}}$ zone are drawn for further investigation of the location of the shear bands for various conditions. To explain the role of $\psi$, two more analyses are performed using the MC model for two values of $\psi\left(=16^{\circ}\right.$ and $\left.25^{\circ}\right)$ but constant $\phi^{\prime}\left(=44^{\circ}\right)$ for $H / D=1.5$. The force-displacement curve for $\psi=16^{\circ}$ in Fig. 8 shows that $N_{h}$ increases with displacement and reaches the peak of $N_{h p}=8.4$. For $\psi=25^{\circ}, N_{h p}=8.8$ (not plotted in Fig. 8). Similar to Fig. 9(a), the locations of the shear bands are obtained for $u / D=0.12$ and plotted in Fig. 9(b). The shear bands for $\psi=25^{\circ}$ are located outside the shear bands with $\psi=16^{\circ}$, which implies 
that with increase in $\psi$ the size of the failure wedge increases and that in turn produces higher $N_{h p}$

In the MMC model, $\psi$ is not constant but varies with plastic shear strain (Fig. 3). Therefore, in the simulations with the MMC, shear band formation due to post-peak reduction of shear strength initiates when $\gamma^{\mathrm{p}}$ exceeds $\gamma_{p}^{p}$. With increase in lateral displacement of the pipe, strain concentration further increases in the previously formed shear band; however, no significant change in the location and orientation of the shear band is found in this case although $\psi$ gradually reduces to zero at large $\gamma^{\mathrm{p}}$. To verify this, analyses have been performed with $\psi=0$ and $\phi^{\prime}=\phi_{c}^{\prime}=35^{\circ}$ and a smaller failure wedge is found as shown in Fig. 9(b) and this gives $N_{h p}=6.45$. In other words, the mobilized dilation angle during the initiation of the shear band influences the shape of the failure wedge and thereby the reaction force.

Figure 9(a) also shows that the shear band reaches the ground surface at a displacement near the peak. At this stage, the $\gamma^{\mathrm{p}}$ in the major portion of the shear band is sufficiently high to reduce $\phi^{\prime}$ almost to $\phi_{c}^{\prime}$ and $\psi$ to 0 . Because $\phi^{\prime}$ and $\psi$ do not decrease with further increase in $\gamma^{\mathrm{p}}$, the $N_{h}$ remains almost constant between $u / D=0.1$ and 0.4 . However, if analysis is simplified by using $\phi^{\prime}=\phi_{c}^{\prime}$ and $\psi=0$, a smaller failure wedge forms which gives lower reaction force.

The shear band formation for $H / D=5.5$ is different from that of $H / D=1.5$. The calculated $\gamma^{\mathrm{p}}$ using the MMC model at $u / D=0.12$ is shown in Fig. 10(a). The mobilized $\phi^{\prime}$ and $\psi$ at this stage are shown in Figs. 10(b) and 10(c), respectively. As shown in Fig. 3, the maximum values of $\phi^{\prime}$ and $\psi$ are mobilized at $\gamma_{p}^{p}$, and therefore $\phi^{\prime}<\phi_{p}^{\prime}$ and $\psi<\psi_{p}$ in the pre-peak $\left(\gamma_{p}<\gamma_{p}^{p}\right)$ and also in the post-yield $\left(\gamma_{p}>\gamma_{p}^{p}\right)$ conditions. In Figs. 10a-c, the post-peak condition $\left(\gamma_{p}>\gamma_{p}^{p}\right)$ is 
developed in the shear bands near the pipe (colored zone), while in the potential shear band above this (gray zone) some plastic shear strains develop $\left(\gamma_{p}<\gamma_{p}^{p}\right)$ but these remain in the prepeak shear zone. In the colored segments of the shear bands in Figs. 10(b) and 10(c), the mobilized $\phi^{\prime}$ and $\psi$ are in the post-yield while in the gray segments they are in the pre-peak zone. Unlike the simulation for $H / D=1.5$ (Fig. 9a), large segments of the plastic shear zone are in the pre-peak condition (gray) which will gradually change to the post-yield condition with increasing $\gamma_{p}$ due to lateral displacement of the pipe. As the strength of the soil is reduced with $\gamma_{p}$, the postpeak degradation of $N_{h}$ is calculated for this $H / D$ (Fig. 8). As the post-peak softening of stressstrain behaviour is not considered, the MC model cannot simulate the degradation of $N_{h}$ after the peak as shown in Fig. 8.

In summary, the above analyses with the proposed MMC model show not only superior simulation of the force-displacement response but also explain the possible mechanisms involved through close examination of the roles of model parameters and burial depth. The peak force could be matched using representative values of $\phi^{\prime}$ and $\psi$ in the MC model. However, if the variation of mobilized $\phi^{\prime}$ and $\psi$ with plastic shear strain and mean effective stress is considered the insight into the mechanisms of pipeline-soil interaction could be better explained.

However, it is noted here that FE element size influences the results when the analyses involve post-peak softening behavior of the soil. Gylland (2012) presented a summary of regularization techniques available in the literature to reduce mesh dependency. Robert (2010) used a simple element size scaling rule for pipeline-soil interaction analysis. An improved regularization technique, considering the orientation of the curved shear bands, likely involves considerable additional complexity and will be left for a future study. 


\section{Parametric study}

Guo and Stolle (2005) compiled a large number of test results from 11 experimental studies and showed that various factors (e.g. $H, D, D_{r}, \phi^{\prime}$ ) influence the dimensionless force $N_{h}$. A parametric study is presented in this section in which only one parameter is varied while the other parameters are kept constant as listed in Table 1, unless otherwise mentioned.

\subsection{Effect of $H / D$}

The $H / D$ ratio could be varied by changing the value of $H$ or $D$ or both. To show the effects of $H / D$, a total of $10 \mathrm{FE}$ analyses are conducted with the MMC model for the following configurations: (i) $D=102 \mathrm{~mm}, H / D=1.5,5.5,6,10$; (ii) $D=150 \mathrm{~mm}, H / D=4,6$; (iii) $D=300 \mathrm{~mm}$, $H / D=2,4,6,10$.

Figure 11 shows the force-displacement curves for a given $H / D(=6)$ but for three different diameters. At $u_{p}$, the mean effective stress $p^{\prime}$ around the pipe is higher for larger diameter pipe. The higher $p^{\prime}$ has two effects: (i) lower mobilized $\phi^{\prime}$ and $\psi$, and (ii) higher $\gamma_{p}^{p}$ required to mobilize $\phi_{\mathrm{p}}^{\prime}$ and $\psi_{\mathrm{p}}$ (cf. Fig. 3 and 6a). Because of these two reasons, the $N_{h p}$ reduces and $u_{p} / D$ increases with diameter. Compiling the results of model tests in dense sand, Guo and Stolle (2005) showed the trend of decreasing $N_{h p}$ with increase in $D$. This implies that the present FE analyses could successfully simulate this trend.

Figures 12 and 13 show the effects of $H$ and $D$ on force-displacement curves when one of them is varied keeping the other one fixed. The increase of $H$ or reduction of $D$, increases the $H / D$ ratio. In both cases (Figs. 12 and 13) $N_{h p}$ and $u_{p} / D$ increase with $H / D$, which is consistent with model tests and FE results (Audibert and Nyman 1977; Trautmann 1983; Guo and Stolle 2005). 
The peak dimensionless force $N_{h p}$ is one of the main parameters used in current pipeline design practice. The calculated values of $N_{h p}$ with the MMC model are plotted with $H / D$ ratio on Fig. 14. For comparison, the results of physical model tests and some FE analyses available in the literature are also plotted on this figure. The $N_{h p}$ increases with $H / D$. The present FE analyses calculate lower rate of increase of $N_{h p}$ at higher $H / D$ ratio. This trend is similar to the model tests of Dickin and Leung (1985). As discussed before, $p^{\prime}$ around the pipe increases with depth of burial, and that reduces the mobilized $\phi^{\prime}$ and $\psi$ which in turn results in lower $N_{h p}$. If $\phi^{\prime}$ and $\psi$ are independent of $p^{\prime}$, higher values of $N_{h p}$ could be obtained especially for larger $H / D$ as shown in Fig. 14 calculated by Yimsiri et al. (2004) with the MC model and Jung et al. (2013) who used the MC model with post-peak softening. Guo and Stolle (2005) also investigated the effects of pressure dependency and showed a significant increase in $N_{h p}$ at low $H / D$ when $\phi_{p}^{\prime}$ increases with $p^{\prime}$ and $\psi$ remains constant. However, with the present MMC model, that increase of $N_{h p}$ at low $H / D$ is not found because the maximum limit of $I_{R}=4$ is used (Bolton 1986; White et al. 2008) and in all the analyses with the MMC model $\psi$ varies with plastic shear strain. A comparison between the results for $D=102 \mathrm{~mm}$ and $300 \mathrm{~mm}$ shows that a lower pipe diameter gives consistently higher $N_{h p}$ at a given $H / D$, which is consistent with the model test results compiled by Guo and Stolle (2005) and Dickin and Leung (1985) as shown in Fig. 14. The possible reasons behind this are explained in previous sections.

\subsection{Effect of model parameters $A_{\psi}$ and $k_{\psi}$}

As discussed in Section 2, for the PS condition Bolton (1986) recommended $A_{\psi}=5.0$ for use in Eq. (1). Analyzing test results on Toyoura sand, Chakraborty and Salgado (2010) recommended $A_{\psi}=3.8$ for both TX and PS conditions. Figure 15 shows the force-displacement curves for 
$A_{\psi}=3.8$ and 5.0 for different $H / D$ but the same pipe diameter $(D=300 \mathrm{~mm})$. For a given $I_{R}, \phi^{\prime}{ }_{C}$ and $k_{\psi}$, the peak friction angle $\phi_{p}^{\prime}$ and dilation angle $\psi_{\mathrm{p}}$ increase with $A_{\psi}$ as defined in Eqs. (1) and (2), which increase the mobilized $\phi^{\prime}$ and $\psi$ (Eqs. 5-8). Because of this, $N_{h p}$ increases with $A_{\psi}$. Moreover, $u_{p} / D$ also increases with $A_{\psi}$.

The soil failure due to lateral displacement of a buried pipe is generally categorized into two simple modes, namely the "wedge" mode in shallow burial conditions and the "plow through" mode in deep burial conditions (e.g. O'Rourke and Liu, 2012). For shallow burial in dense sand, the drained lateral displacement of the pipe results in upward and lateral movement of a soil wedge that is assumed to slide along either a straight (triangular wedge) or curved (log-spiral wedge) line. On the other hand, for deep burial conditions, the lateral movement of the pipe results in soil flow around the pipe with negligible deformation at the ground surface. Further discussion on failure mechanisms is provided in the following sections.

A close examination of progressive development of shear bands shows that for $H / D=2$ and 4 the wedge while for $H / D=10$ the plow through mode governs the response. For $H / D=6$, wedge type of failure occurs when $A_{\psi}=3.8$ is used, while the failure is very similar to plow through mode for $A_{\psi}=5.0$. In other words, in the transition zone (from shallow to deep) the failure mechanism is influenced by this parameter, and therefore a significant difference between calculated $N_{h}$ is found for $H / D=6$.

Similar to $A_{\psi}$, different values of $k_{\psi}$ were obtained from test results on different sands (Bolton 1986; Chakraborty and Salgado 2010; Xiao 2014). Figure 16 shows the force-displacement curves for three different values of $k_{\psi}$. For a given $\phi_{p}^{\prime}-\phi_{c}^{\prime}$, the value of $\psi_{\mathrm{p}}$ increases with decrease in $k_{\psi}$ (Eq. 2), which increases mobilized $\psi$ (Eqs. 6 and 8). As discussed before, the size 
of the failure wedge increases with $\psi$, therefore the dimensionless force is higher for lower value of $\psi$ as shown in Fig. 16.

\subsection{Effect of relative density of sand}

As the focus of the present study is to model the response of pipelines in dense sand, the effects of relative density are examined for $D_{r}$ between $70 \%$ and $90 \%$ (Fig. 17). In the analyses, $I_{R}$ in Eq. (1) is calculated for given $D_{r}$. In addition, the unit weight of sand for a given $D_{r}$ is calculated using specific gravity of sand $G_{s}=2.74$ and maximum and minimum densities of 15.5 and 18.3 $\mathrm{kN} / \mathrm{m}^{3}$ (Trautmann 1983). Figure 17 shows that $N_{h p}$ increases with $D_{r}$. However, there is no significant difference between calculated $N_{h}$ at large displacements for different $D_{r}$.

\section{Failure Pattern}

The soil failure mechanisms are explained using the formation of shear bands with lateral displacements. Figures $18(\mathrm{a}-\mathrm{c})$ show the plastic shear strain (field variable FV1 in Abaqus) for three lateral displacements, shown by the points A, B and C in Fig. 13: (i) at $N_{h p}(u / D=0.12)$ (ii) at moderate displacement $(u / D=0.17)$, and (iii) at large displacement $(u / D=0.4)$. At $u / D=0.12$, large plastic shear strains accumulate in narrow zones and two shear bands $f_{1}$ and $f_{2}$ are formed (Fig. 18a). With increase in displacement (e.g. $u / D=0.17$ ) the shear bands $f_{1}$ and $f_{2}$ propagate further upward and also an additional shear band $f_{3}$ is formed (Fig. 18b). At very large displacements (e.g. $u / D=0.4$ ) all the shear bands reach to the ground surface (Fig. 18c). In other words, the failure surfaces develop progressively and mobilized $\phi^{\prime}$ and $\psi$ in the shear band are not constant until large displacements when the soil reaches the critical state. The plastic shear strains in the soil elements outside the shear bands are negligible. Therefore, the soil elements 
bounded by $f_{1}$ and $f_{3}$ displace upward and left as a wedge while another wedge formed by the shear bands $f_{2}$ and $f_{3}$ sinks downward, which is shown by the instantaneous velocity vectors in the right column of Fig. 18. The shear bands in Fig. 18(c) are very similar to model tests of Turner (2004) in dense sand. Shear bands of almost similar pattern are also found in the FE simulations with the MMC model for $H / D \leq 6$. Moreover, as shown in Figs. 18(a)-(c), significant plastic strains develop in the shear band which could be successfully simulated using Abaqus/Explicit without numerical issues due to significant mesh distortion.

The soil failure mechanisms at large displacements for $H / D=10$ (Fig. 19) are different from Fig. 18. The plastic shear strain concentration mainly occurs near the pipe instead of reaching the ground surface. The shear bands are not symmetric above and below the centre of the pipe rather the shear bands propagate more above the pipe. Behind the pipe, the plastic shear strains develop in a relatively large zone and sand moves into the gap created by pipe displacements. The instantaneous velocity vectors show that the soil element flow mainly occurs above the pipe. Jung et al. (2013) suggested that burial depths of $15-23 D$ are required for the symmetric flow of soil around the pipe. As the burial depth considered in this study is not sufficient for flow around mechanism, $N_{h p}$ increases monotonically with $H / D$ even at $H / D=10$ (Fig. 14), which should approach a horizontal asymptote at large $H / D$ (Jung et al. 2013).

\section{Conclusions}

The response of buried pipelines subjected to lateral ground movement is critical for safe and reliable design of pipelines. In this study, the lateral pipeline-soil interaction is investigated using comprehensive FE analyses. One of the key components that significantly influences the success of FE analyses of pipeline-soil interaction is the constitutive behaviour used for modeling the soil. In this study, a modified Mohr-Coulomb (MMC) model is proposed which has 
limited complexity but sufficient to capture most of the important features of stress-strain behaviour of dense sand such as the nonlinear pre- and post-peak variation of the angle of internal friction and dilation angle with plastic shear strain, loading conditions, density and mean effective stress. A method to implement the MMC in Abaqus using a user subroutine is presented. The FE results with the MMC are compared with FE results obtained with the conventional Mohr-Coulomb (MC) model and experimental results. The following conclusions can be drawn from this study.

a) The failure surfaces develop progressively with lateral displacement of the pipe. The mobilized $\phi^{\prime}$ and $\psi$ are not constant along the shear bands although constant values are used in the conventional MC model.

b) The shear band formation and the mobilized values of $\phi^{\prime}$ and $\psi$ along the shear band significantly influence the shape of the force-displacement curves. For the same sand, postpeak degradation of $N_{h}$ is observed at intermediate burial depth (e.g. $H / D=5.5$ in Fig. 8), while $N_{h}$ remains almost constant for shallow depths (e.g. $H / D=1.5$ ). The present MMC model is shown capable of simulating this.

c) The mobilized dilation angle $\psi$ significantly influences the shape of the failure wedge and thus the reaction force on the pipeline.

d) The variation of calculated peak dimensionless force $\left(N_{h p}\right)$ with $H / D$ using the present MMC model is consistent with previous experimental results and numerical analyses; however, the pressure and plastic shear strain dependency of $\phi^{\prime}$ and $\psi$ in the MMC model gives better simulation of lateral resistance $\left(N_{h}\right)$ for a wide range of lateral displacements including the post-peak reduction of $N_{h}$. 
e) The depth of embedment for transition from shallow to deep failure mechanisms is influenced by the soil parameters $A_{\psi}$. For a higher value of $A_{\psi}$, the plow through mechanism develops at shallower depths resulting in higher lateral resistance.

\section{Acknowledgements}

The works presented in this paper have been supported by the Research and Development Corporation of Newfoundland and Labrador and the Natural Sciences and Engineering Research Council of Canada (NSERC).

\section{List of symbols}

The following abbreviations and symbols are used in this paper:

$\begin{array}{ll}T X & \text { Triaxial } \\ P S & \text { Plane strain } \\ D S & \text { Direct shear } \\ M C & \text { Mohr-Coulomb model with constant } \phi^{\prime} \text { and } \psi \\ M M C & \text { Modified Mohr-Coulomb model with mobilized } \phi^{\prime} \text { and } \psi \text { as Fig. } 3 \\ A_{\psi} & \text { Slope of }\left(\phi_{p}^{\prime}-\phi_{c}^{\prime}\right) \text { vs. } I_{R} \text { in Eq. }(1) \\ m, C_{1}, C_{2} & \text { Soil parameter (Eqs. } 3 \text { and } 4) \\ D & \text { Pipeline diameter } \\ E & \text { Young's modulus } \\ H & \text { Distance from ground surface to the centre of pipe } \\ I_{R} & \text { Relative density index } \\ K & \text { Material constant }\end{array}$


$K_{0} \quad$ Earth pressure coefficient at rest

$N_{h} \quad$ Lateral dimensionless force

$N_{h p} \quad$ Peak lateral dimensionless force

$Q, R \quad$ Material constant (Bolton 1986)

$k_{\psi} \quad$ Slope of $\left(\phi_{p}^{\prime}-\phi_{c}^{\prime}\right)$ vs. $\psi_{p}$ in Eq. (2)

$p^{\prime} \quad$ Mean effective stress

$q \quad$ Deviatoric stress

$u \quad$ Lateral displacement of pipe

$u_{p} \quad$ Lateral displacement at $N_{h p}$

$\mu \quad$ Friction coefficient between pipeline and soil

$v \quad$ Poisson's ratio

$\varepsilon_{a}^{p} \quad$ Axial strain at the peak stress ratio

$\varepsilon_{1}^{p} \quad$ Major principal plastic strain

$\varepsilon_{3}^{p} \quad$ Minor principal plastic strain

$\sigma_{c} \quad$ Confining pressure

$\phi^{\prime} \quad$ Mobilized angle of internal friction

$\phi_{\text {in }}^{\prime} \quad \phi^{\prime}$ at the start of plastic deformation

$\phi_{p}^{\prime} \quad$ Peak friction angle

$\phi_{c}^{\prime} \quad$ Critical state friction angle

$\phi_{p}^{\prime P S} \quad$ Peak friction angle in plane strain condition

$\phi_{p}^{\prime T X} \quad$ Peak friction angle in triaxial condition

$\phi^{\prime D S} \quad$ Angle of internal friction in direct shear test 


$\begin{array}{ll}\phi_{p}^{\prime D S} & \text { Peak friction angle in direct shear condition } \\ \phi_{\mu} & \text { Pipe-soil interface friction angle } \\ \psi & \text { Mobilized dilation angle } \\ \psi_{p} & \text { Peak dilation angle } \\ \psi_{\text {in }} & \quad \text { at the start of plastic deformation }(=0) \\ \gamma^{p} & \text { Engineering plastic shear strain } \\ \gamma_{p}^{p} & \gamma^{\mathrm{p}} \text { required to mobilize } \phi_{p}^{\prime} \\ \gamma_{c}^{p} & \text { Strain softening parameter }\end{array}$

\section{References}

Ahmed, S.M.U. 1973. A study of the influence of confining pressure on the behaviour of sands. M.Sc. Thesis, McGill University, Montreal, Canada.

Almahakeri, M., Fam, A., and Moore, I.D. 2012. The flexural behaviour of buried steel and composite pipes pulled relative to dense sand: experimental and numerical investigation. 9th Int. Conf. on Pipelines IPC2012, September 24-28, Calgary, AB, Canada. IPC 2012-90158. pp. 9.

Almahakeri, M., Fam, A., and Moore, I.D. 2014. Experimental investigation of longitudinal bending of buried steel pipes pulled through dense sand. Journal of Pipeline Systems Engineering and Management, ASCE, 5(2). doi: 10.1061/(ASCE)PS.1949-1204.0000141.

Almahakeri, M., Fam, A., and Moore, I.D. 2013. Longitudinal bending and failure of GFRP pipes buried in dense sand under relative ground movement. Journal of Composites for Construction, ASCE, 17(5):702-710. 
American Lifelines Alliance. 2005. Seismic design guidelines for water pipelines. American Lifelines Alliance in partnership with the Federal Emergency Management Agency, Washington, D.C. Available from www.americanlifelinesalliance.org [accessed 4 April 2015].

Audibert, J.M.E., and Nyman, K.J. 1978. Soil restraint against horizontal motion of pipes. International Journal of Rock Mechanics and Mining Sciences and Geomechanics Abstracts, 15(2): A29-A29.

Bishop, A. W. 1961. Discussion on soil properties and their measurement. Proceedings of 5 th Int. Conf. on Soil mechanics and Foundation engineering, vol. III.

Bolton, M. D. 1986. The strength and dilatancy of sands. Geotechnique, 36(1):65-78.

Burnett, A. J. 2015. Investigation of full scale horizontal pipe-soil interaction and large strain behaviour of sand. MASc. thesis, Queen's University, Kingston, Ontario, Canada.

Chakraborty, T., and Salgado, R. 2010. Dilatancy and shear strength of sand at low confining pressures. Journal of Geotechnical and Geoenvironmental Engineering, 136(3):527-532.

Conforth, D.H. 1964. Some experiments on the influence of strain conditions on the strength of sand. Geotechnique, 14:143-167.

Dafalias, Y. F., and Herrmann, L. R. 1982. Bounding surface formulation of soil plasticity. Soil Mechanics-Transient and Cyclic Loads. Pande, G. N. and Zienkiewicz, O. C., Eds., John Wiley and Sons, New York, NY.

Dafalias, Y. F., and Manzari, M. 2004. Simple plasticity sand model accounting for fabric change effects. ASCE Journal of Engineering Mechanics, 130(6): 622-634. 
Daiyan, N., Kenny, S., Phillips, R., and Popescu, R. 2011. Investigating pipeline-soil interaction under axial-lateral relative movements in sand. Canadian Geotechnical Journal, 48(11):1683-1695.

Davis, E. H. 1968. Theories of plasticity and the failure of soil masses. In Soil mechanics: Selected topics (ed. I. K. Lee), London: Butterworth. pp. 341-380.

Dickin, E.A., and Leung, C.F. 1983. Centrifugal model tests on vertical anchor plates. Journal of Geotechnical Engineering, 109(12):1503-1525.

DNV 2007 (Det Norske Veritas). DNV-OS-F101. Available from https://exchange.dnv.com/servicedocuments/dnv/ [accessed 4 April 2015].

Ellis, E.A., and Springman, S.M. 2001. Modelling of soil-structure interaction for a piled bridge abutment in plane strain FEM analyses. Computers and Geotechnics, 28(2):79-98. doi:10.1016/S0266-352X(00)00025-2.

Gajo, A., and Muir Wood, D. 1999. A kinematic hardening constitutive model for sands: the multiaxial formulation. International Journal for Numerical and Analytical Methods in Geomechanics, 23(9): 925-965.

Guo, P., and Stolle, D. 2005. Lateral pipe-soil interaction in sand with reference to scale effect. Journal of Geotechnical and Geoenvironmental Engineering, 131(3):338-349.

Gylland A. S. 2012. Material and slope failure in sensitive clays. PhD thesis, Norwegian University of Science and Technology.

Hardin, B .O., and Black, W. L. 1966. Sand stiffness under various triaxial stress. Journal of the Soil Mechanics and Foundations Division, ASCE, 92(SM2):27-42. 
Hashiguchi, K., and Ueno, M. 1977. Elastoplastic constitutive laws of granular materials, Constitutive Equations of Soils. Proc. 9th Int. Con5 Soil Mech. Found. Eng., Spec. Session S, eds. Murayama, S. and Schofield, A. N., JSSMFE, Tokyo. pp. 73-82.

Honegger, D., and Nyman, D.J. 2004. Guidelines for the seismic design and assessment of natural gas and liquid hydrocarbon pipelines. Pipeline Research Council International, Catalog No. L51927, October.

Houlsby, G.T. 1991. How the dilatancy of soils affects their behaviour. Invited Theme Lecture, Proceedings of the Tenth European Conference on Soil Mechanics and Foundation Engineering, Florence, May 27-30, Vol. 4, ISBN 90-5410-005-2. pp. 1189-1202.

Hsu, S.T., and Liao, H.J. 1998. Uplift behaviour of cylindrical anchors in sand. Canadian Geotechnical Journal, 35(1):70-80.

Janbu, N. 1963. Soil compressibility as determined by oedometer and triaxial tests. Proceedings, European Conference on Soil Mechanics and Foundations Engineering, Wiesbaden, Germany, Vol. 1. pp.19-25.

Jardine, R. J. 1992. Nonlinear stiffness parameters from undrained pressuremeter Tests. Canadian Geotechnical Journal, 29(3):436-447. doi: 10.1139/t92-048.

Jefferies, M., and Been, K. 2000. Soil liquefaction: a critical state approach. Taylor \& Francis, New York.

Jung, J., O’Rourke, T., and Olson, N. 2013. Lateral soil-pipe interaction in dry and partially saturated sand. Journal of Geotechnical and Geoenvironmental Engineering, 139(12): $2028-2036$.

Jung, J., O'Rourke, T., and Olson, N. 2013. Uplift soil-pipe interaction in granular soil. Canadian Geotechnical Journal, 50(7):744-753. doi: 10.1139/cgj-2012-0357. 
Kolymbas, D, and Wu, W. 1990. Recent results of triaxial tests with granular materials. Powder Technology, 60(2):99-119.

Kouretzis, G.P., Sheng, D., and Sloan, S.W. 2013. Sand-pipeline-trench lateral interaction effects for shallow buried pipelines. Computers and Geotechnics, 54:53-59.

Kulhawy, F.H., and Mayne, P.W. 1990. Manual on estimating soil properties for foundation design. Report EPRI-EL 6800, Electric Power Research Institute, Palo Alto. pp. 306.

Lancelot, L, Shahrour, I, and Mahmoud, MA. 2006. Failure and dilatancy properties of sand at relatively low stresses. J. Eng. Mech, ASCE, 132(12):1396 -1399.

Lee, K. L., and Seed, H. B. 1965. Drained strength characteristics of sands. Journal of the Soil Mechanics and Foundations Division, ASCE, 93(6):117-141.

Lings, M. L., and Dietz, M. S. 2004. An improved direct shear apparatus for sand. Geotechnique, 54(4):245-256.

Mitchell, J.K., and Soga, K., 2005. Fundamentals of soil behavior. 3rd Edition. John Wiley \& Sons, Hoboken.

Moore, I.D. and Booker, J.R., 1987. Ground failure around buried tubes. International Journal of Rock Mechanics and Rock Engineering, 20(4):243-260.

Mroz, Z. 1967. On the description of anisotropic work hardening. J. Mech. Phys. Solids. 15:163-175.

O’Rourke, and M.J., Liu, X. 2012. Seismic design of buried and offshore pipelines. MCEER Monograph, MCEER-12-MN04.

Pike, K., Kenny, S., and Hawlader, B. 2013. Advanced analysis of pipe/soil interaction accounting for strain localization. Proceeding, GéoMontréal 2013, the 66th Canadian 
Geotechnical Conference and the 11th Joint CGS/IAH-CNC Groundwater Conference, Montreal, Canada.

Pradhan, T.B.S., Tatsuoka, F., and Horii, N. 1988. Strength and deformation characteristics of sand in torsional simple shear. Soils and Foundations, 28(3):131-148.

Prevost, J.H. 1985. A simple plasticity theory for frictional cohesionless soils. Soil Dynamics and Earthquake Engineering, 4(1): 9-17.

Qiu G, Henke S, and Grabe J. 2009. Applications of coupled Eulerian-Lagrangian method to geotechnical problems with large deformations. Proceeding of SIMULIA customer conference 2009, London, UK. pp. 420-435.

Robert, D. J. 2010. Soil-pipeline interaction in unsaturated soils. PhD thesis, University of Cambridge, United Kingdom.

Rowe, P. W. 1969. The relation between the shear strength of sands in triaxial compression, plane strain and direct shear. Geotechnique, 19(1):75-86.

Scarpelli, G., Sakellariadi, E., and Furlani, G. 1999. Longitudinal pipeline-soil interaction: results from field full scale and laboratory testing. Twelfth European Conference on Soil Mechanics and Geotechnical Engineering. pp. 511.

Schanz, T., and Vermeer, P. A. 1996. Angles of friction and dilatancy of sand. Geotechnique, 46(1):145-151.

Simoni, A., and Houlsby, G. T. 2006. The direct shear strength and dilatancy of sand-gravel mixtures. Geotechnical \& Geological Engineering, 24(3):523-549.

Taleb, B. and Moore, I.D., 1999. Metal culvert response to earth loading - Performance of two-dimensional analysis. Transportation Research Record No. 1656, Underground and Other Structural Design Issues. National Research Council, Washington. pp. 25-36. 
Tatsuoka, F., Sakamoto, M., Kawamura, T., and Fukushima, S. 1986. Strength and deformation characteristics of sand in plane strain compression at extremely low pressures. Soils and Foundations, 26(1):65-84.

Tatsuoka, F., Siddiquee, M. S. A., Park, C-S, Sakamoto, M. and Abe, F. 1993. Modeling stressstrain relations of sand. Soils and Foundations, 33(2):60-81.

Taylor, D. W. 1948. Fundamentals of soil mechanics. New York: Wiley.

Trautmann, C. 1983. Behavior of pipe in dry sand under lateral and uplift loading. PhD thesis, Cornell University, Ithaca, NY.

Turner, J. P., and Kulhawy, F. H. 1987. Experimental analysis of drilled shaft foundations subjected to repeated axial loads under drained conditions. Rep. to Electric Power Research Institute, Cornell University, Ithaca, NY.

Turner, J.E. 2004. Lateral force-displacement behavior of pipes in partially saturated sand. M.S. Thesis, Cornell University, Ithaca, NY.

Vermeer, P. A. and de Borst, R. 1984. Non-associated plasticity for soils, concrete and rock. HERON, 29(3):1-64.

White, D. J., Cheuk, C. Y., and Bolton, M. D. 2008. The uplift resistance of pipes and plate anchors buried in sand. Geotechnique, 58(10), 771-777.

Wijewickreme, D., Karimian, H., and Honegger, D. 2009. Response of buried steel pipelines subjected to relative axial soil movement. Canadian Geotechnical Journal, 46(7):735-735.

Wood, D. M. 2007. The magic of sands - The 20th Bjerrum Lecture presented in Oslo, 25 November 2005. Canadian Geotechnical Journal, 44(11):1329-1350. doi: 10.1139/T07-060.

Xie, X. 2008. Numerical analysis and evaluation of buried pipeline response to earthquakeinduced ground fault rupture. PhD thesis, Rensselaer Polytechnic Institute, New York. 
Xiao, Y., Liu, H., Chen, Y., and Chu, J. 2014. Strength and dilatancy of silty sand. ASCE Journal of Geotechnical and Geoenvironmental Engineering, 140(7).

Yimsiri, S., Soga, K., Yoshizaki, K., Dasari, G., and O'Rourke, T. 2004. Lateral and upward soilpipeline interactions in sand for deep embedment conditions. Journal of Geotechnical and Geoenvironmental Engineering, 130(8):830-842.

Yimsiri, S. and Soga, K. 2006. DEM analysis of soil-pipeline interaction in sand under lateral and upward movements at deep embedment. Journal of Southeast Asian Geotechnical Society, 37:83-94.

Yoshimine, M. 2005. Archives-soil mechanics laboratory. Tokyo Metropolitan University, Retrieved from http://geot.civil.ues.tmu.ac.jp/archives/ [accessed 4 April 2015] 


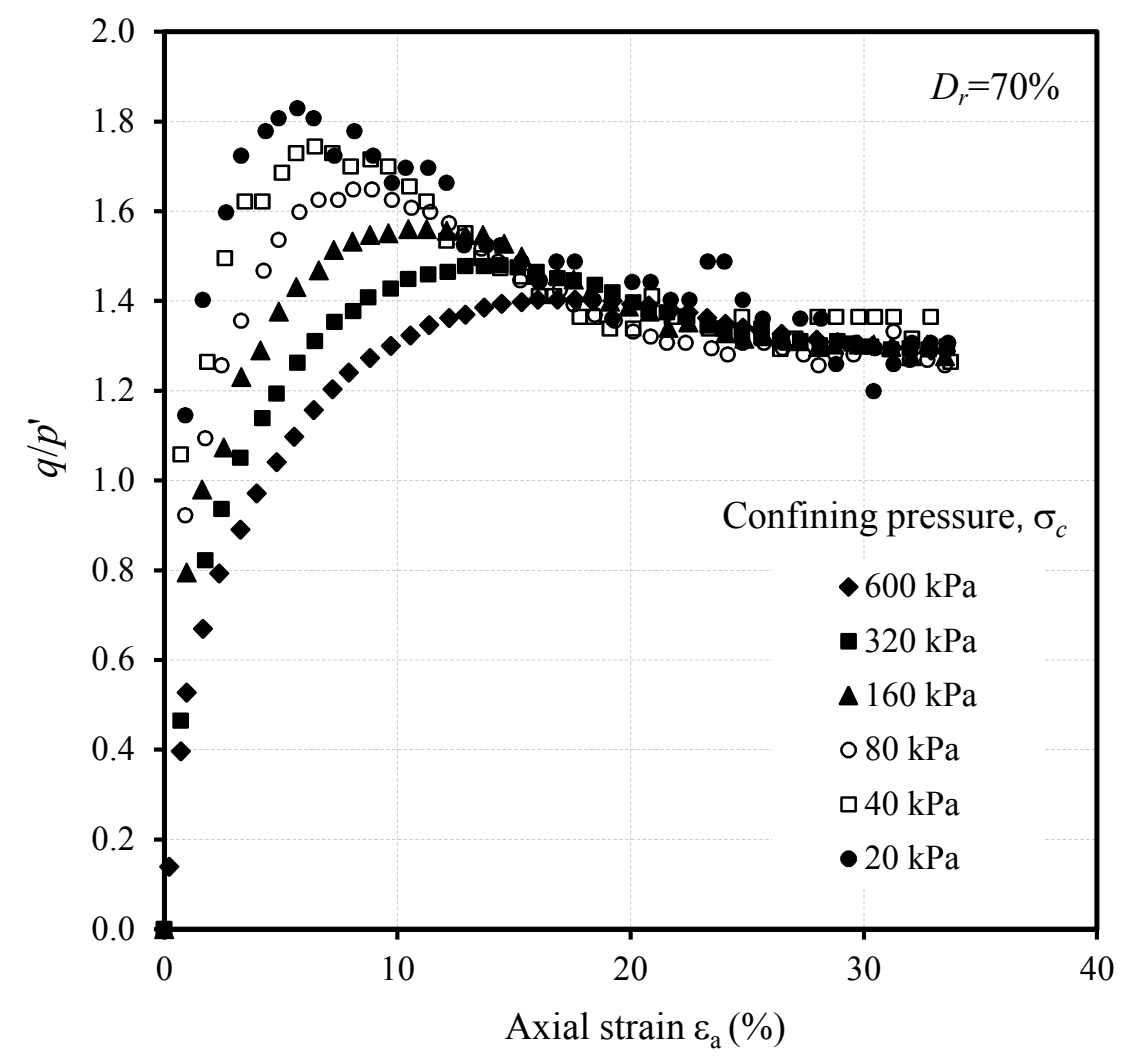

Fig. 1. Consolidated isotropically drained triaxial test results on dense sand (after Hsu and Liao 1998): (a) stress-strain behaviour 


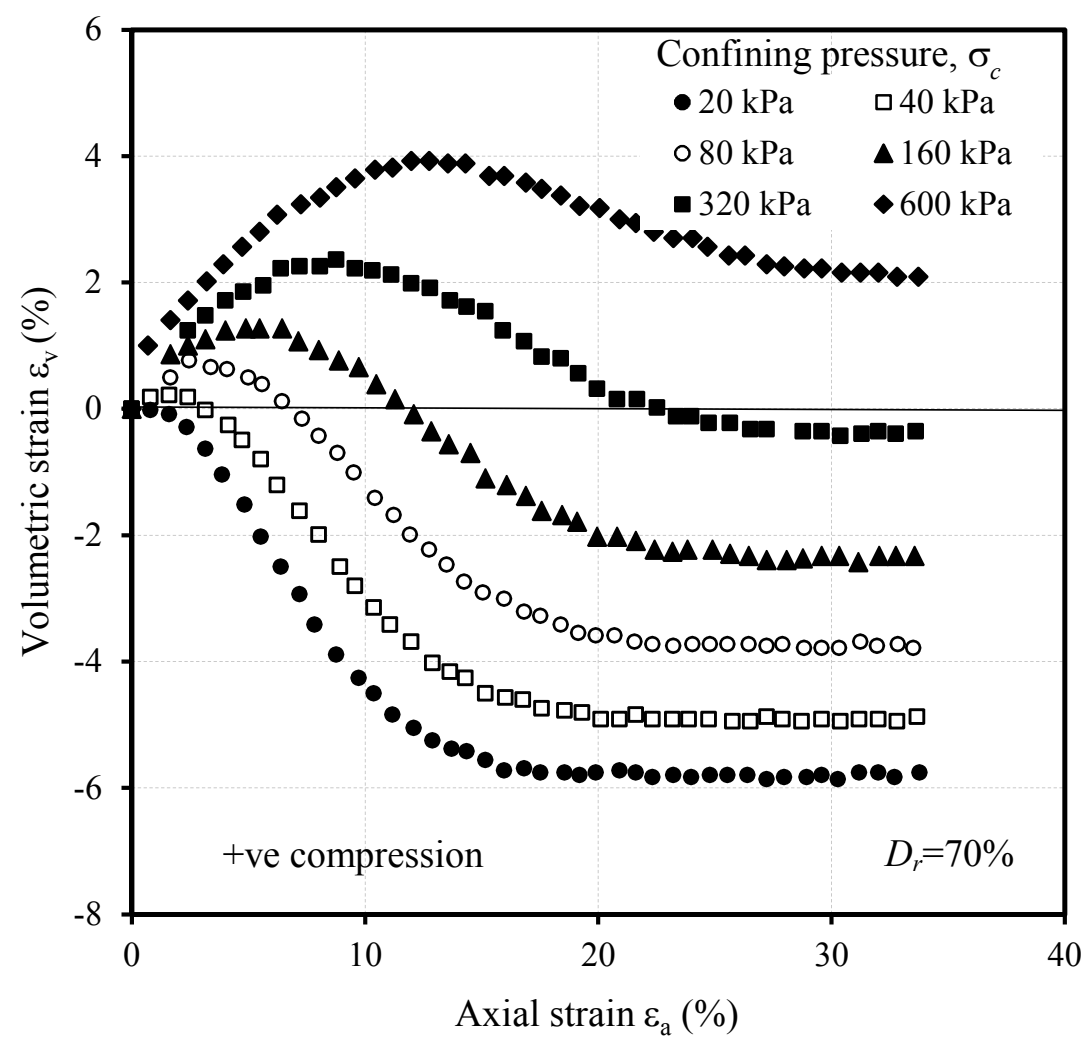

Fig. 1. Consolidated isotropically drained triaxial test results on dense sand (after Hsu and Liao 1998): (b) volume change behaviour 


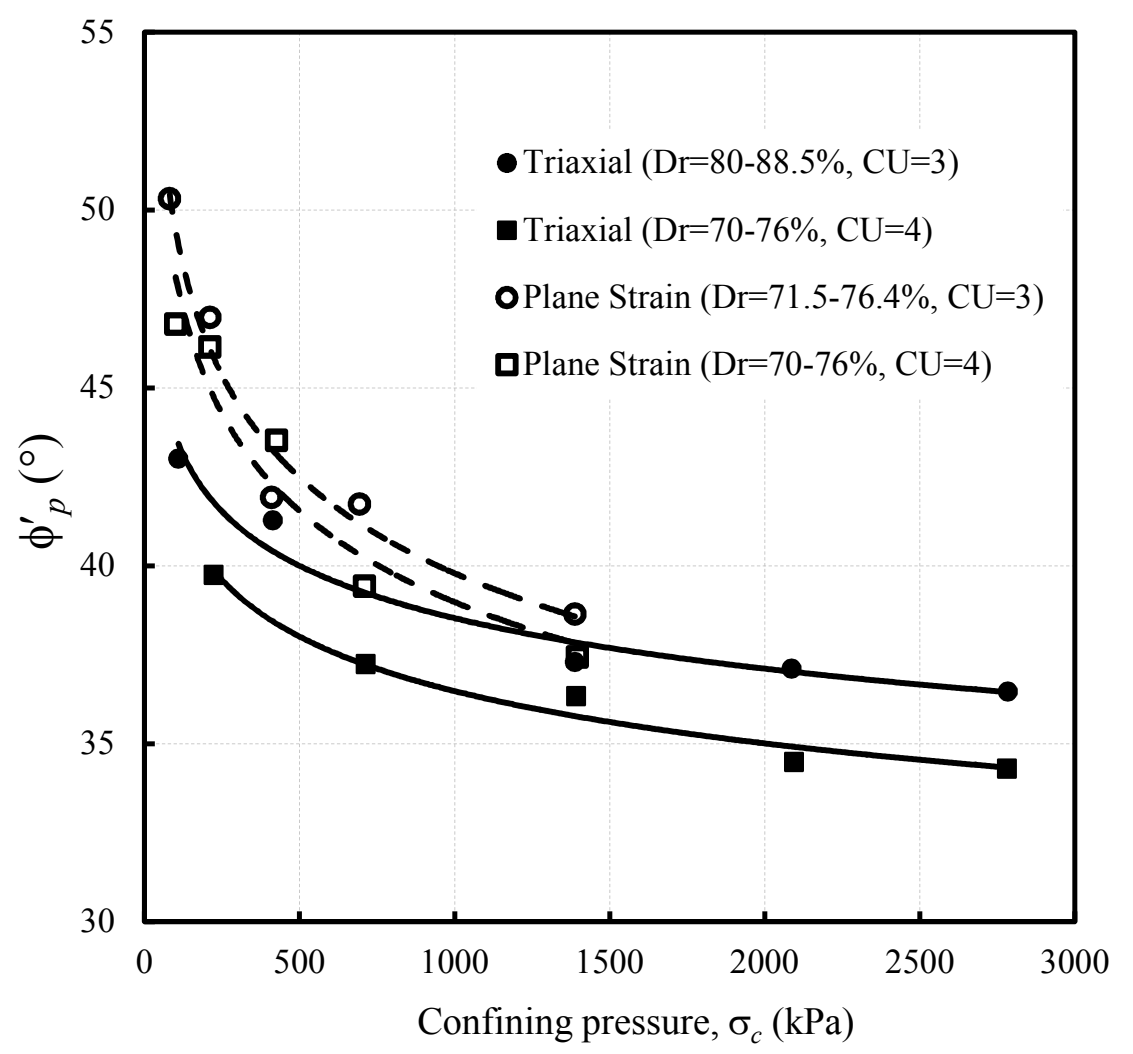

Fig. 2. Peak friction angle of crushed silica sand from triaxial and simple shear tests (after Ahmed 1973) 


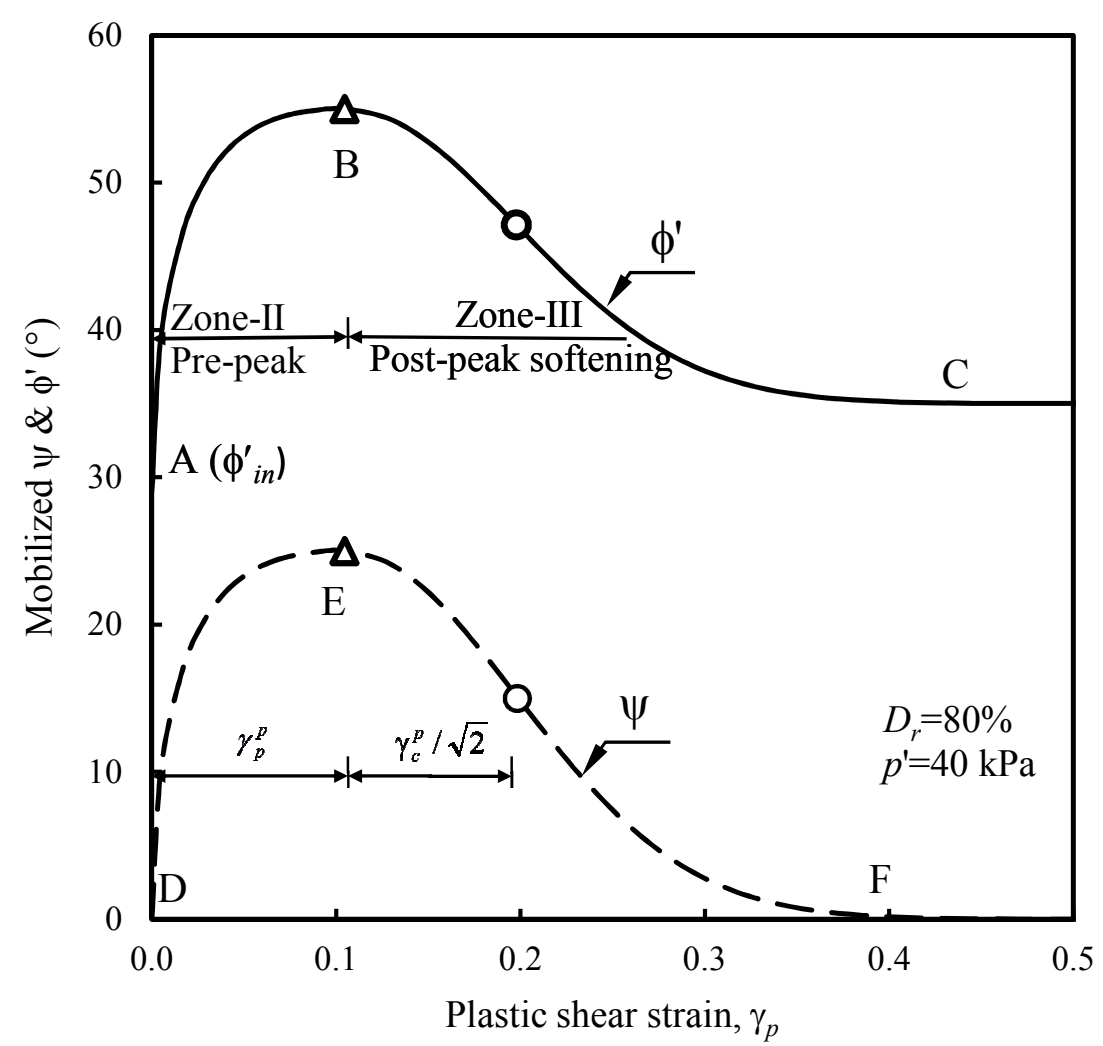

Fig. 3. Modeling of stress-strain behavior of dense sand using modified Mohr-Coulomb (MMC) model (plane strain condition) 


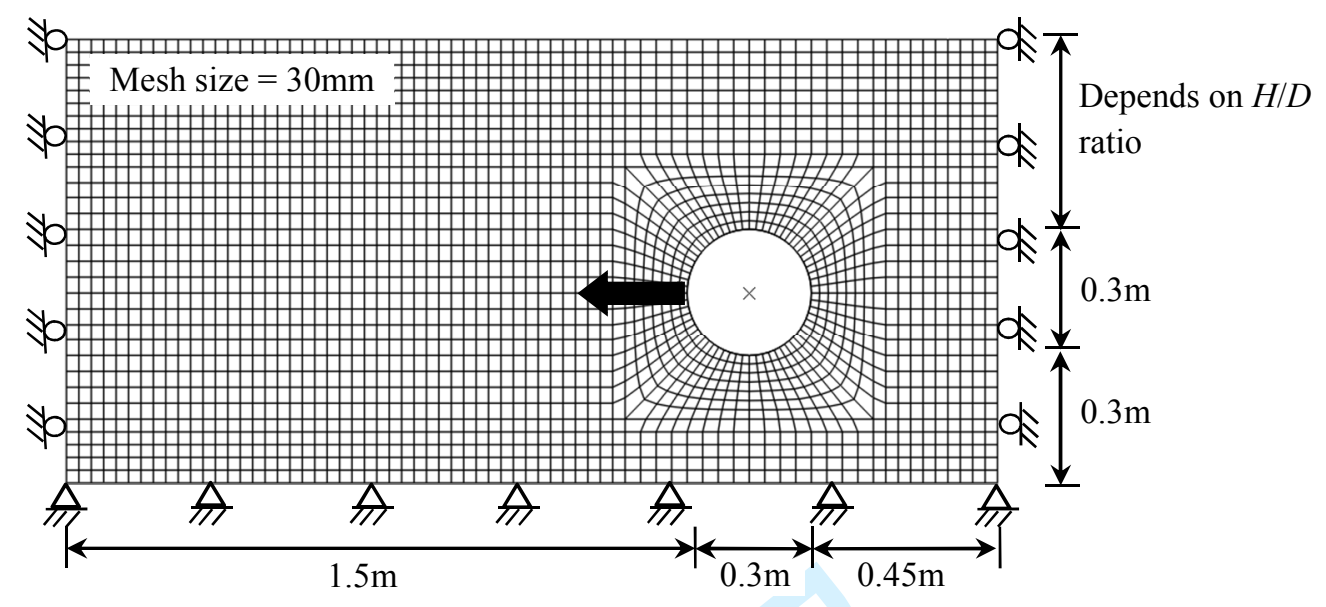

Fig. 4. Typical finite element mesh for $H / D=2$ and $D=300 \mathrm{~mm}$ 


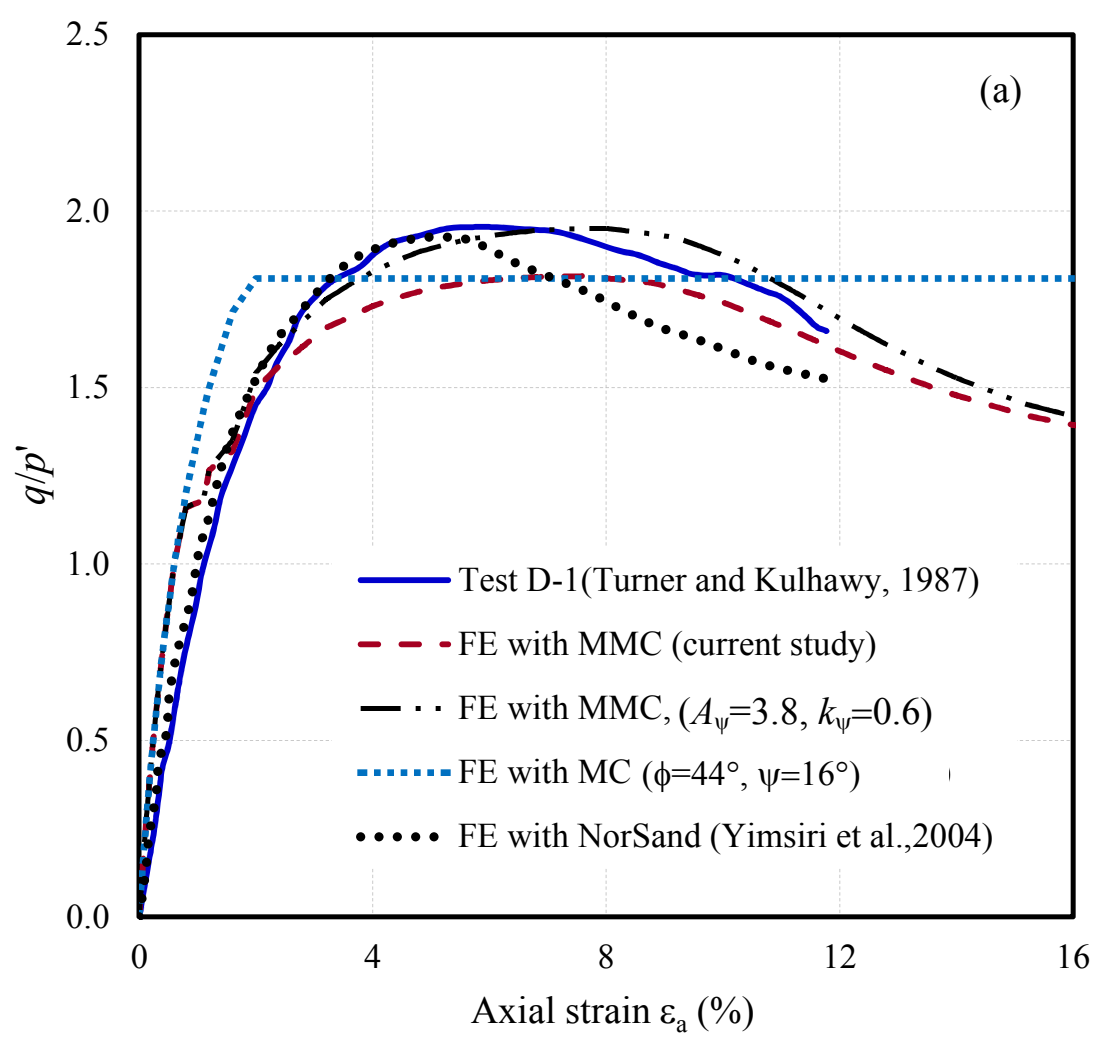

Fig. 5. Comparison of FE and triaxial compression tests results $\left(\sigma_{\mathrm{c}}=39 \mathrm{kPa}, D_{r}=80 \%\right)$ : (a) stressstrain behaviour 


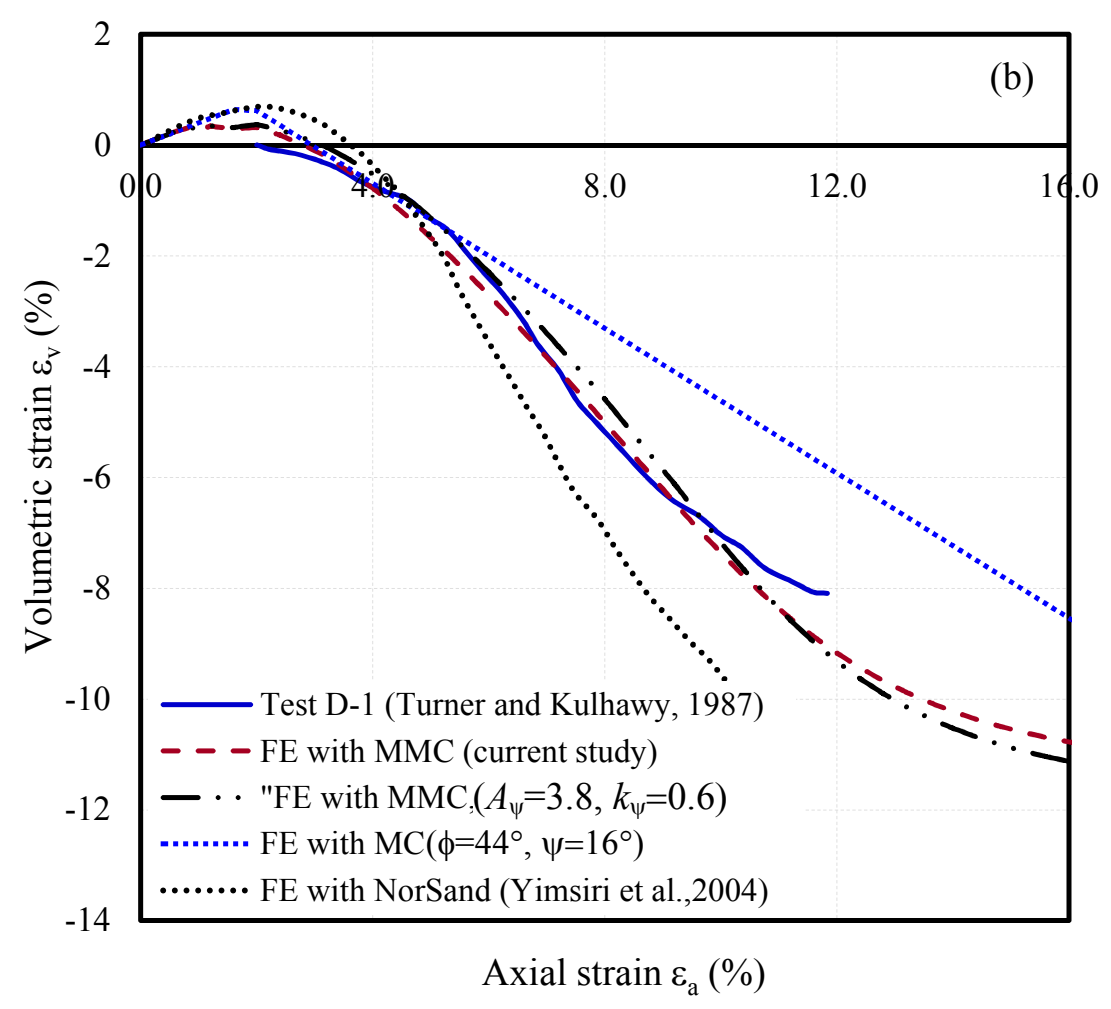

Fig. 5. Comparison of $\mathrm{FE}$ and triaxial compression tests results $\left(\sigma_{\mathrm{c}}=39 \mathrm{kPa}, D_{r}=80 \%\right)$ : (b) volume change behaviour 


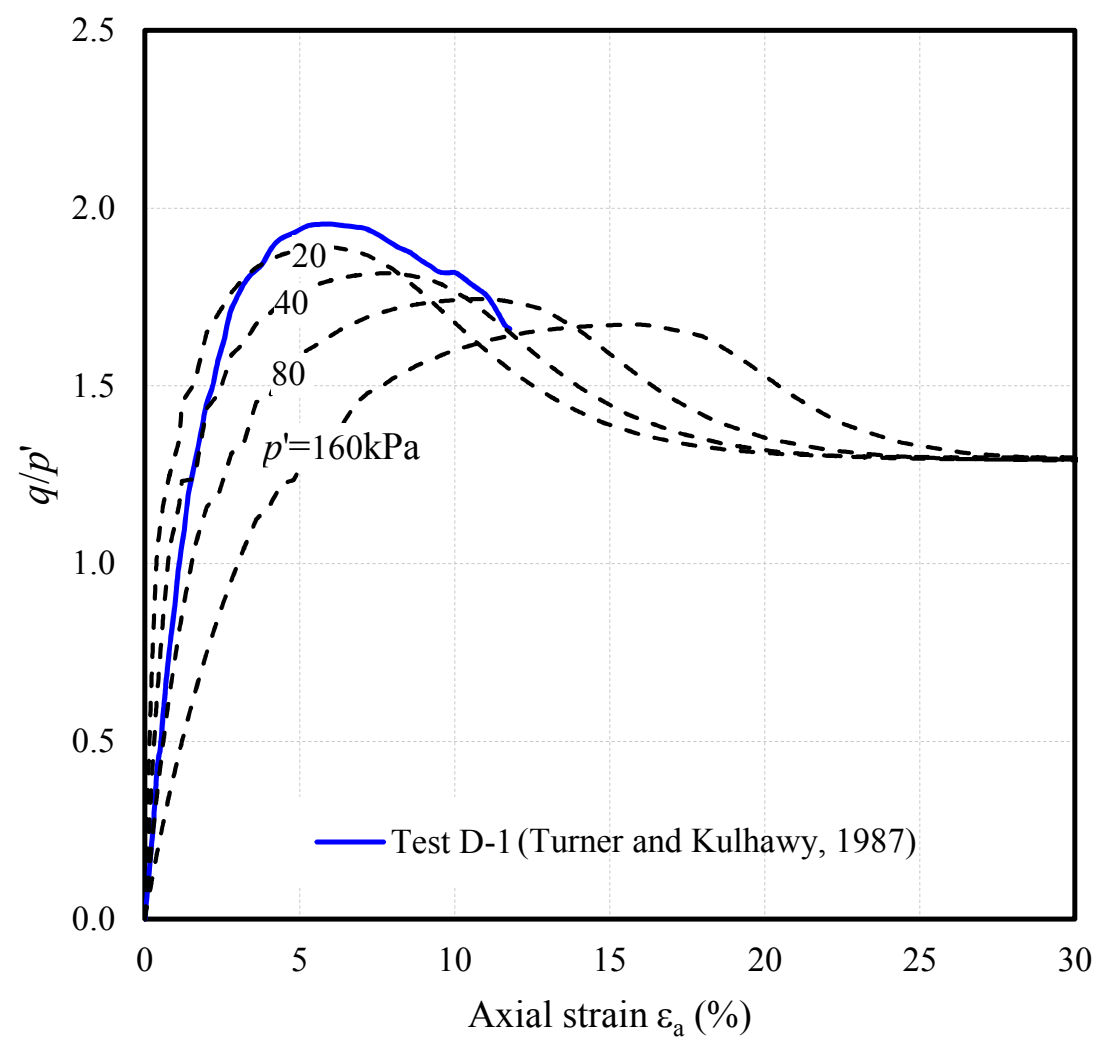

Fig. 6. Effect of confining pressure on triaxial tests $\left(D_{r}=80 \%\right)$ : (a) stress-strain behaviour 


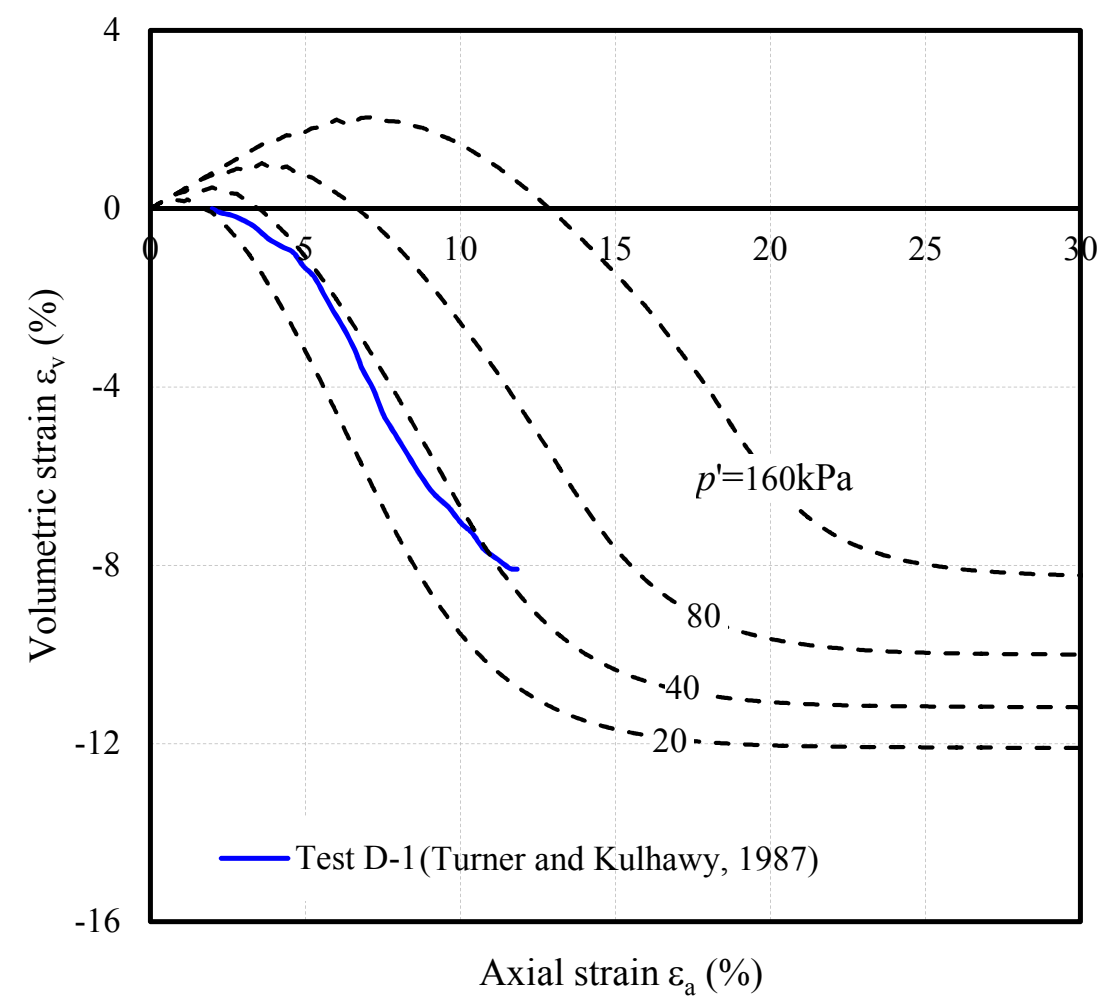

Fig. 6. Effect of confining pressure on triaxial tests $\left(D_{r}=80 \%\right)$ : (b) volume change behaviour 


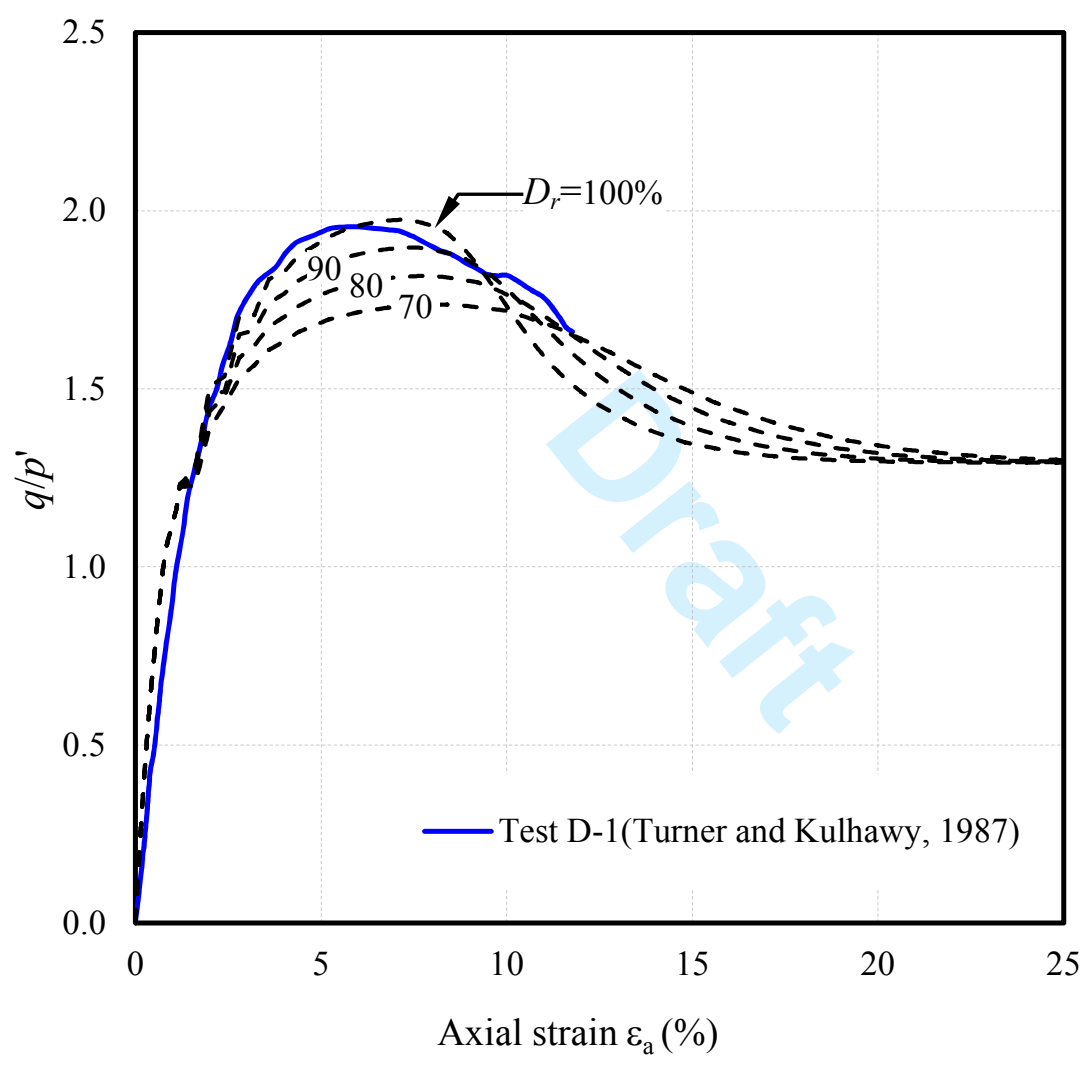

Fig. 7. Effect of relative density: (a) stress-strain behaviour 


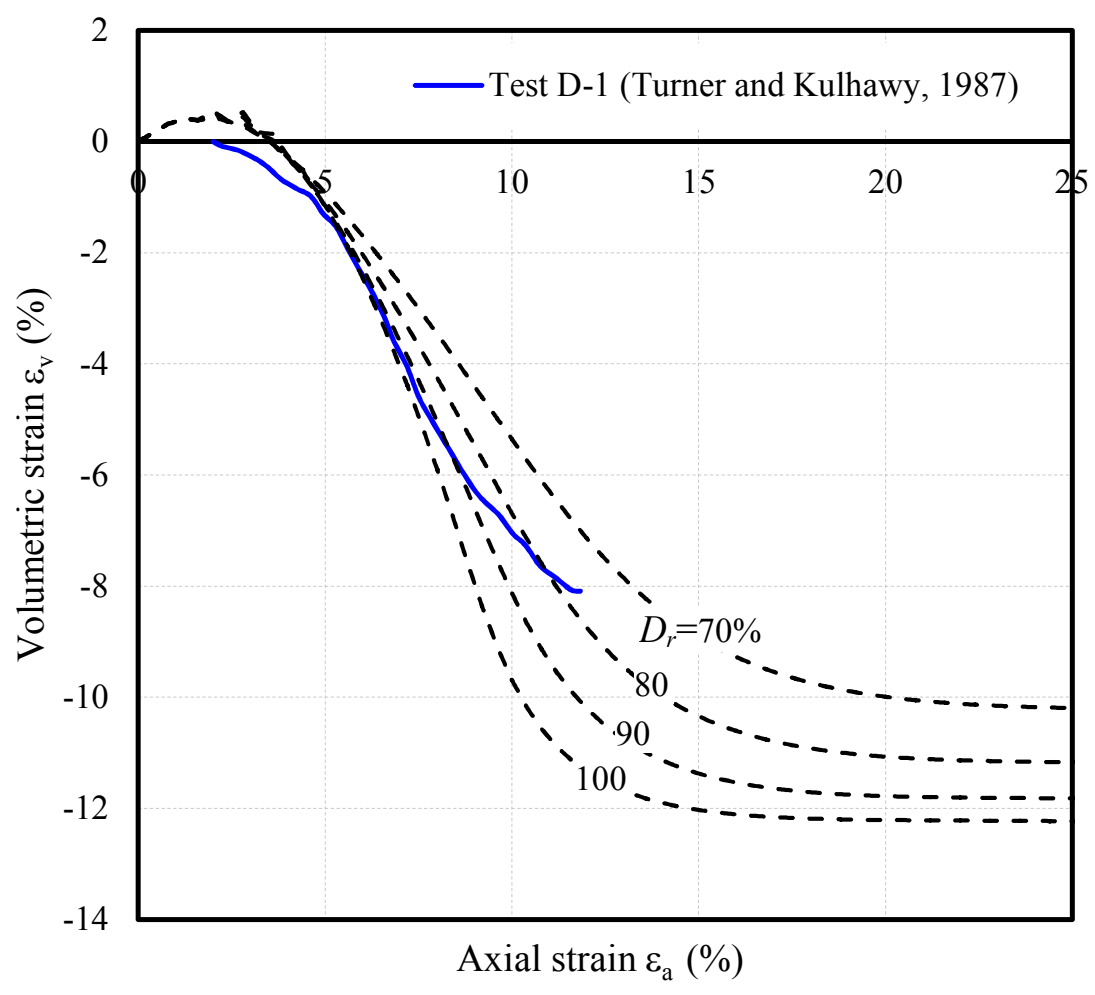

Fig. 7. Effect of relative density: (b) volume change behaviour 


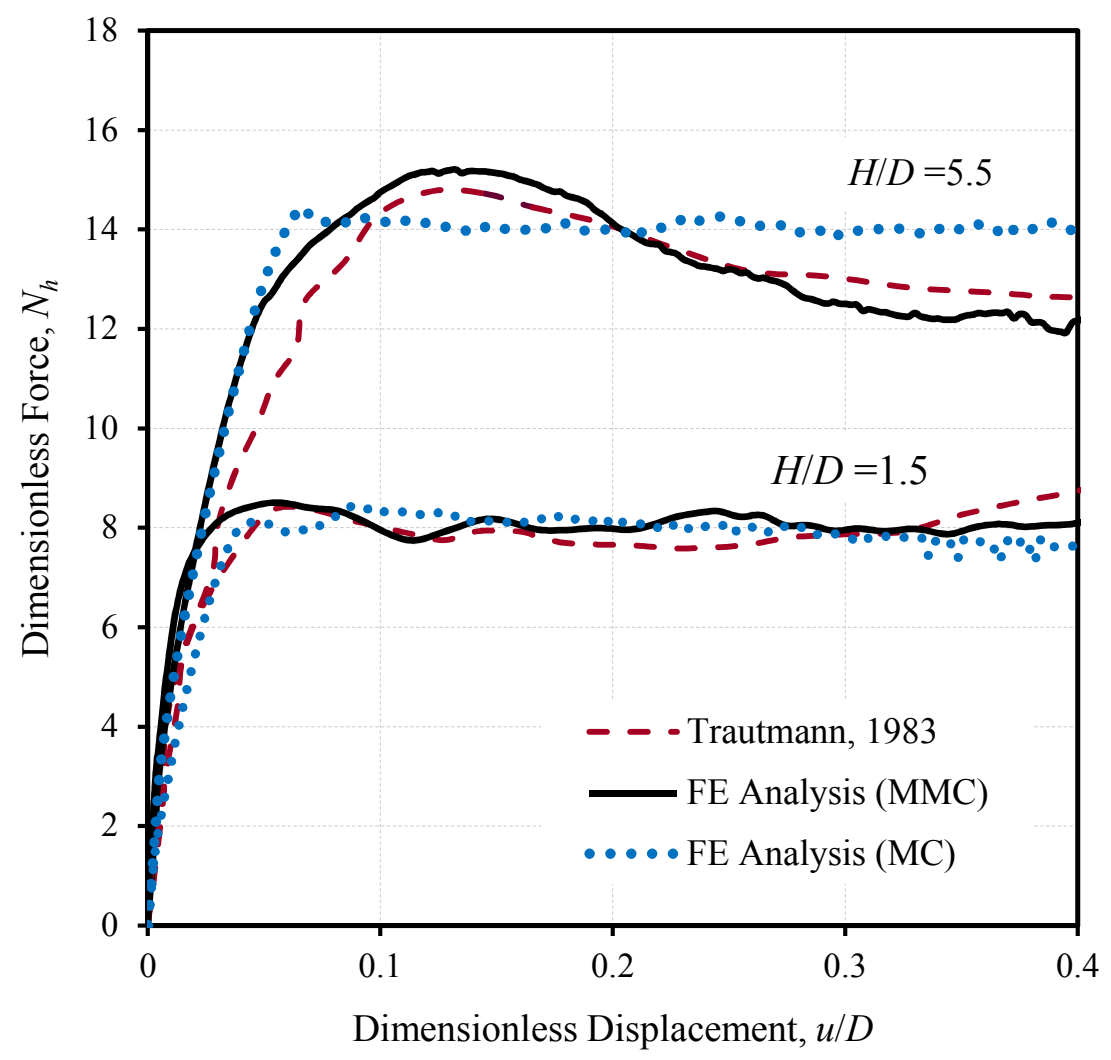

Fig. 8. Comparison of FE results with the large scale test results (Trautmann, 1983) 

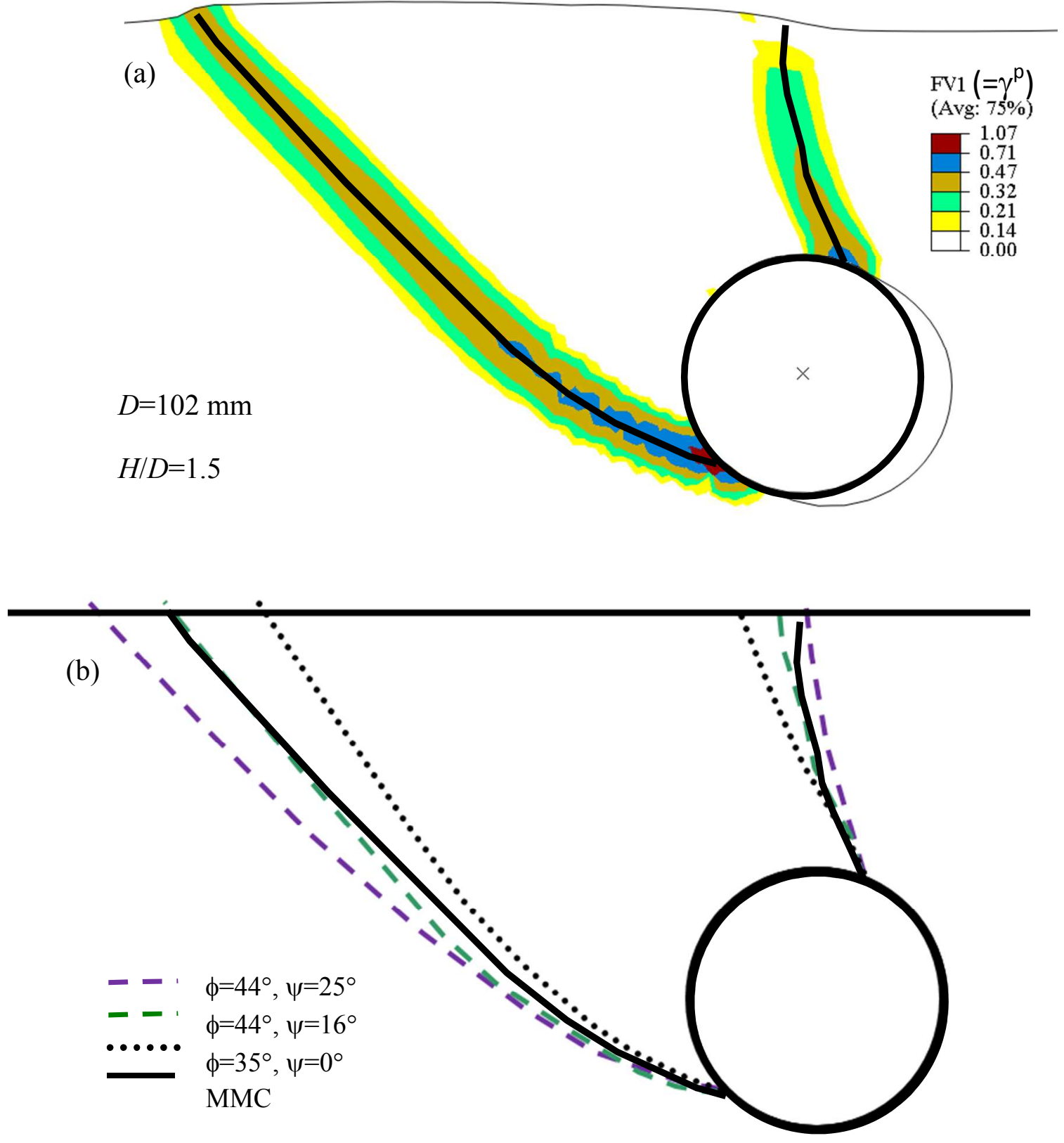

Fig. 9. Location of shear band at $u / D=0.12$ : (a) using MMC (b) using $\mathrm{MC}$ and MMC model 

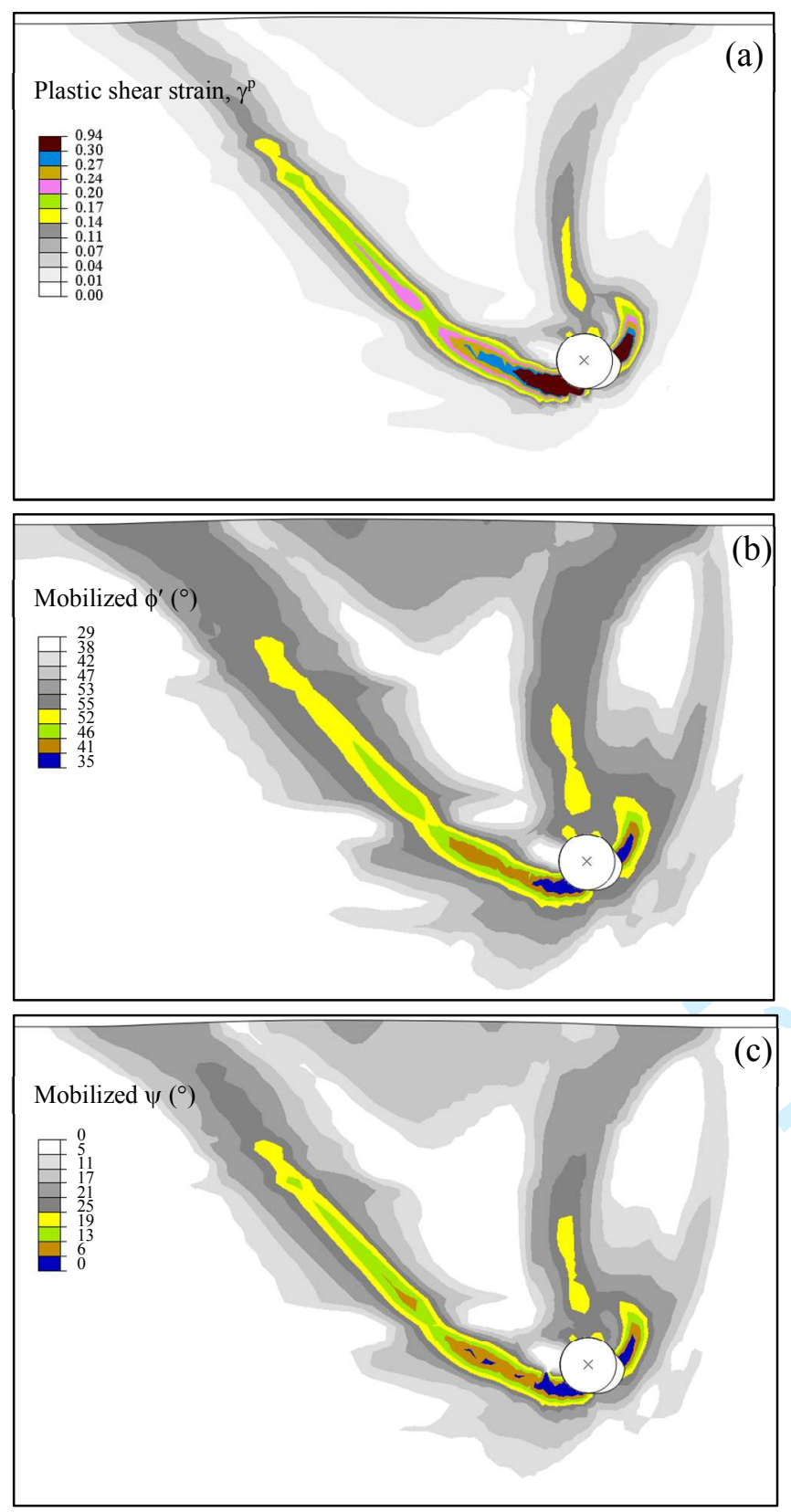

Fig. 10. Shear band formation and strength mobilization for $H / D=5.5$ and $D=102 \mathrm{~mm}$ at $u / D=0.12$ with MMC model: (a) plastic shear strain $\gamma^{\mathrm{p}}$, (b) mobilized $\phi^{\prime}$, (c) mobilized $\psi$ 


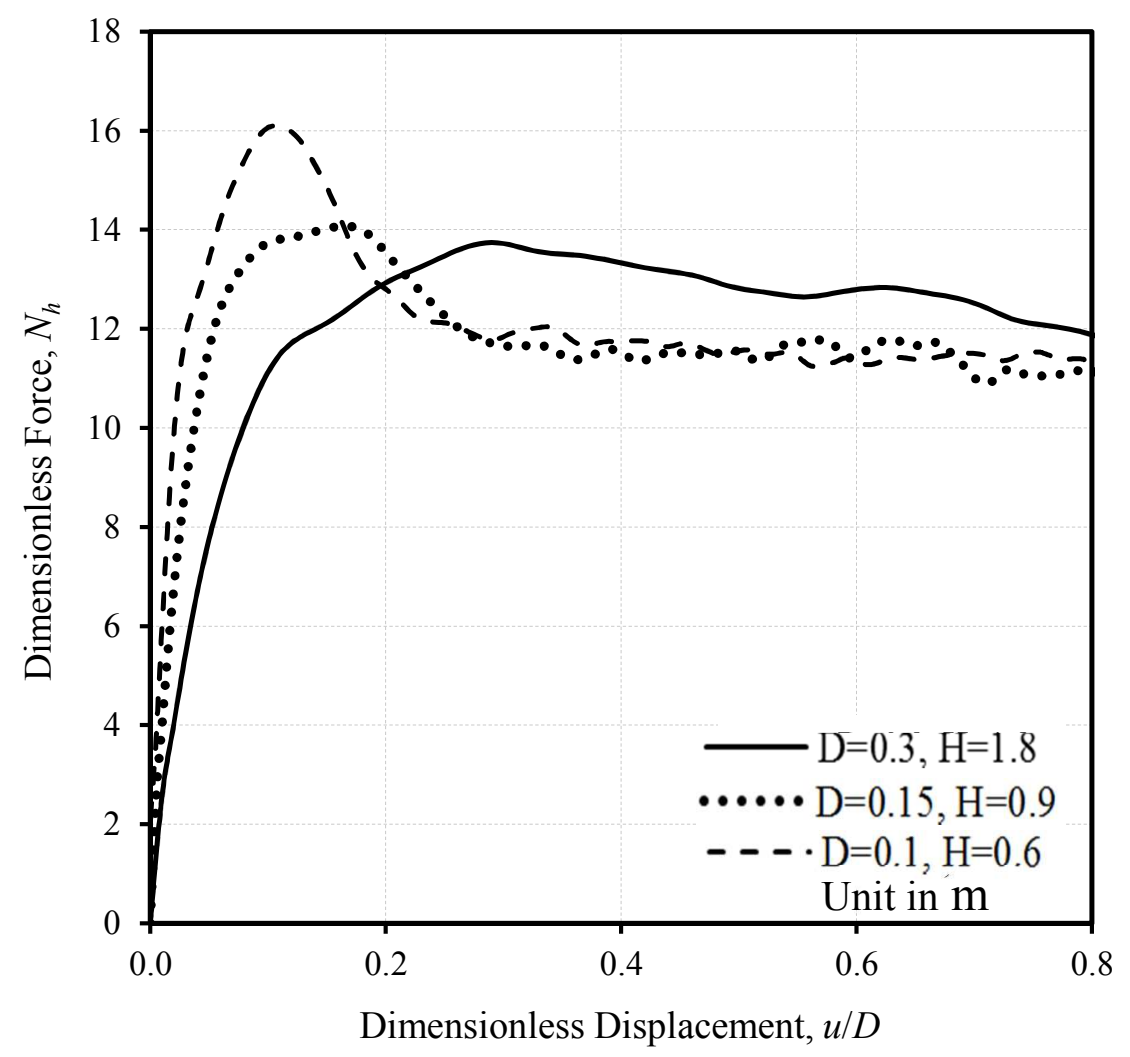

Fig. 11. Effects of diameter on force-displacement curve for $H / D=6$ 


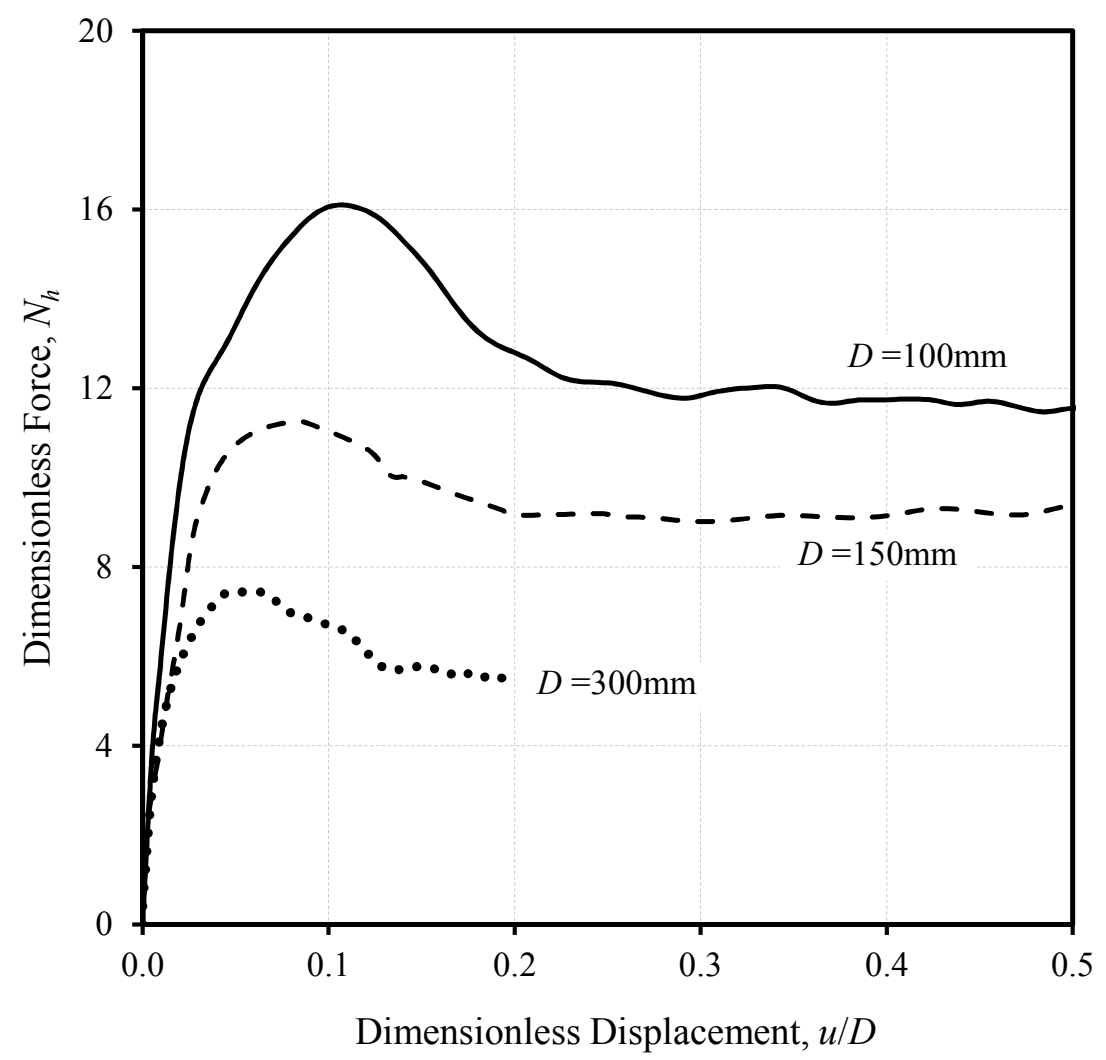

Fig. 12. Effect of pipe diameter on $N_{h}$ for $H=600 \mathrm{~mm}$ 


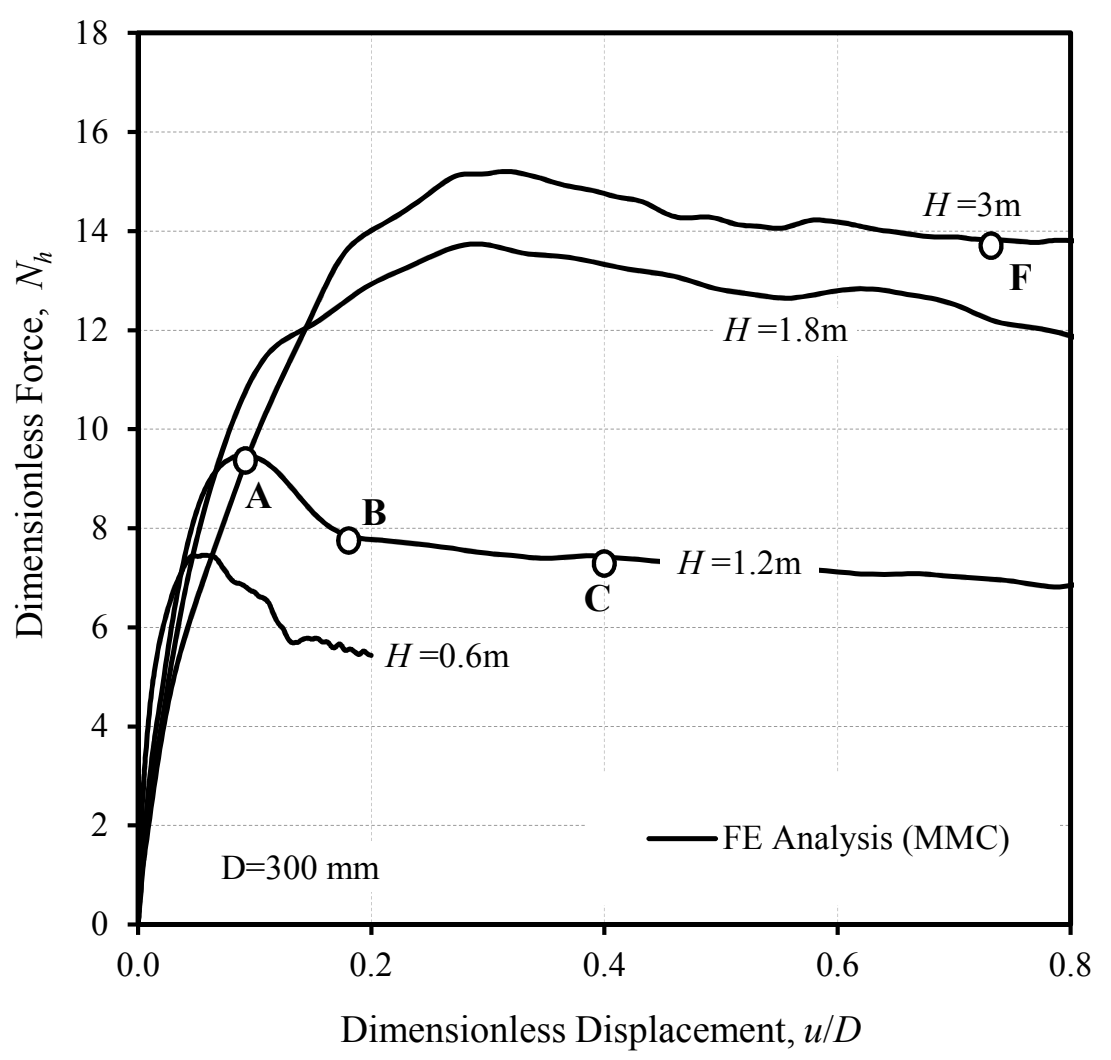

Fig.13. Effects of burial depth on $N_{h}$ for $D=300 \mathrm{~mm}$ 


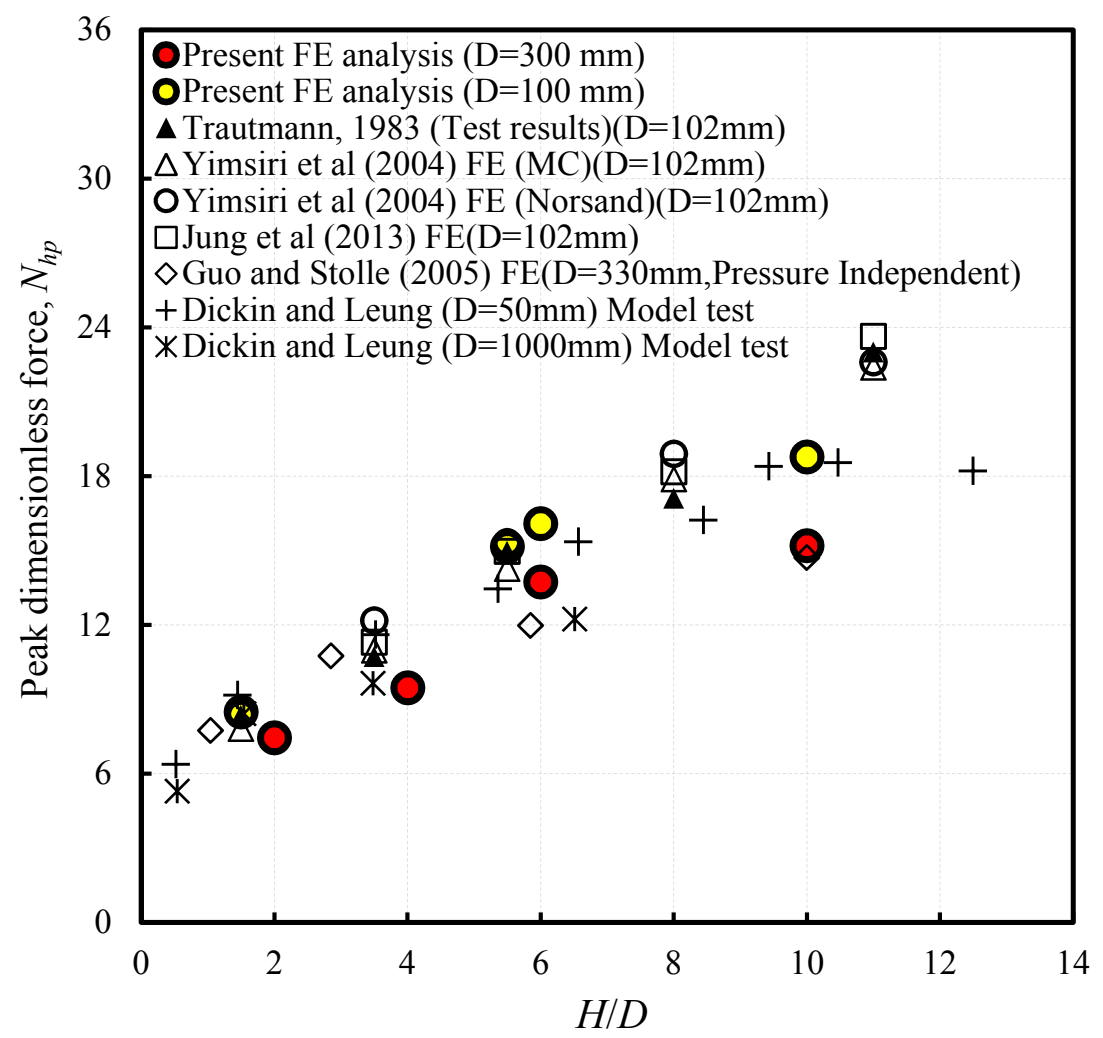

Fig. 14. Comparison of peak resistance $N_{h p}$ with previous studies 


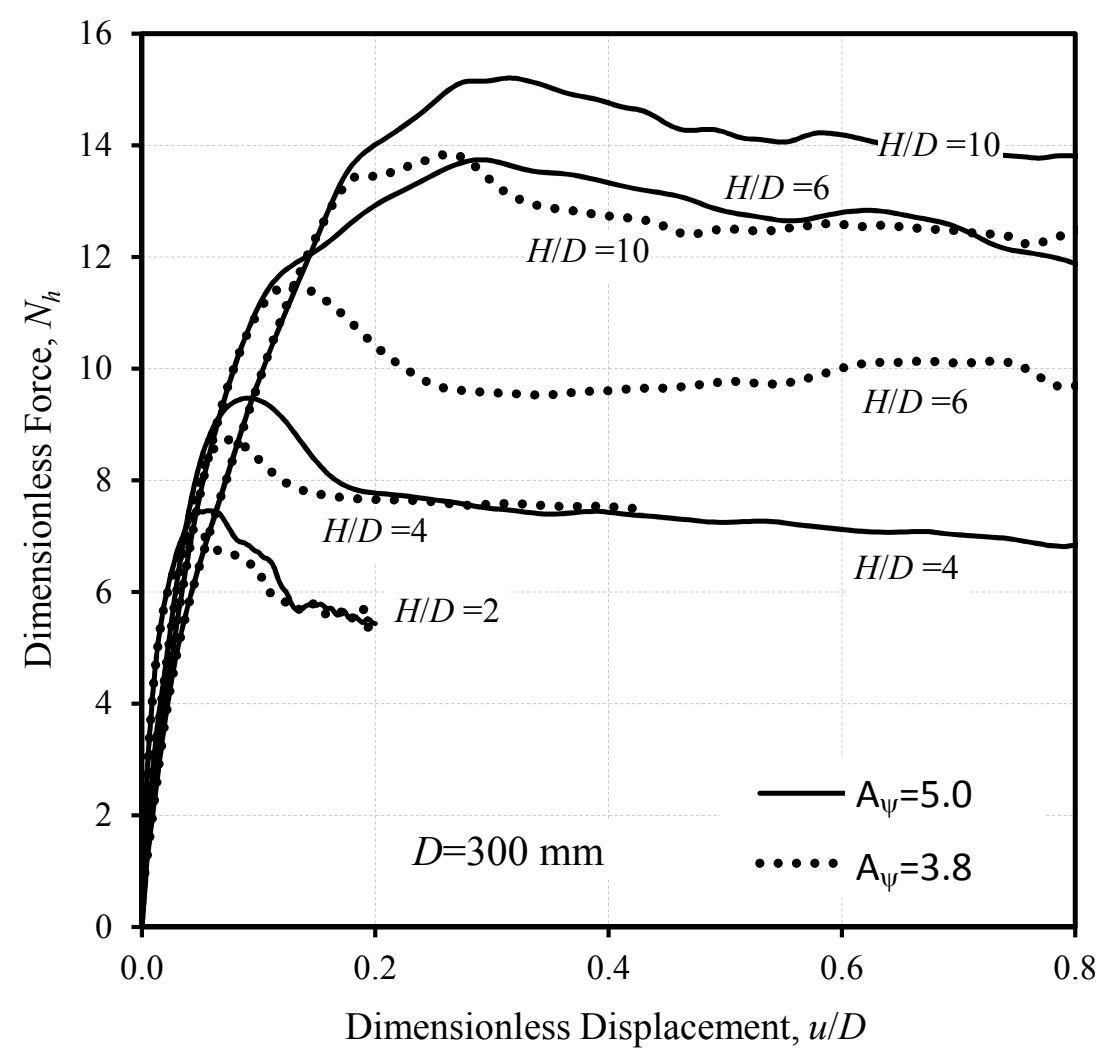

Fig. 15. Effect of $A_{\psi}$ on dimensionless force $N_{h}$ for $D=300 \mathrm{~mm}$ 


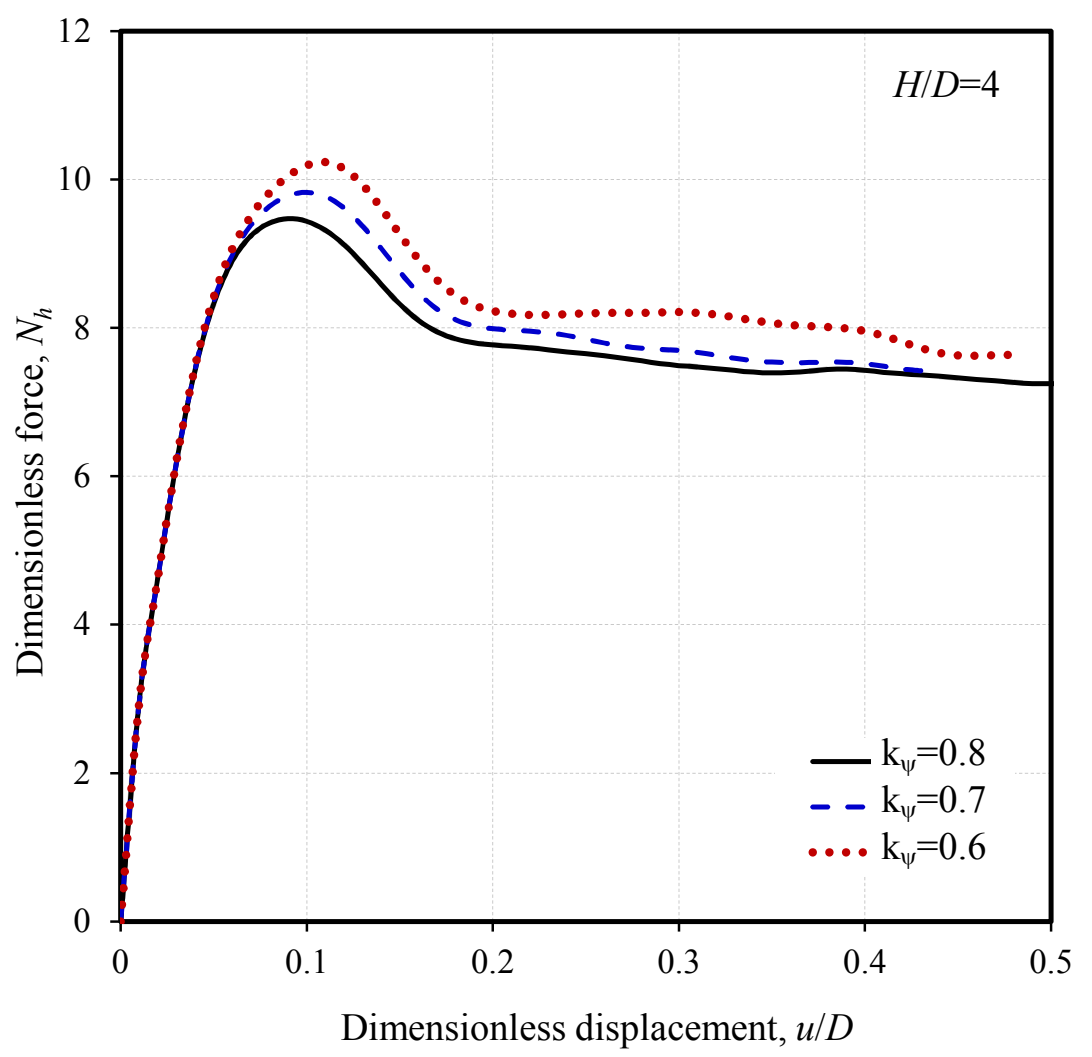

Fig. 16. Effect of $k_{\psi}$ on dimensionless force $N_{h}$ for $H / D=4$ and $D=300 \mathrm{~mm}$ 


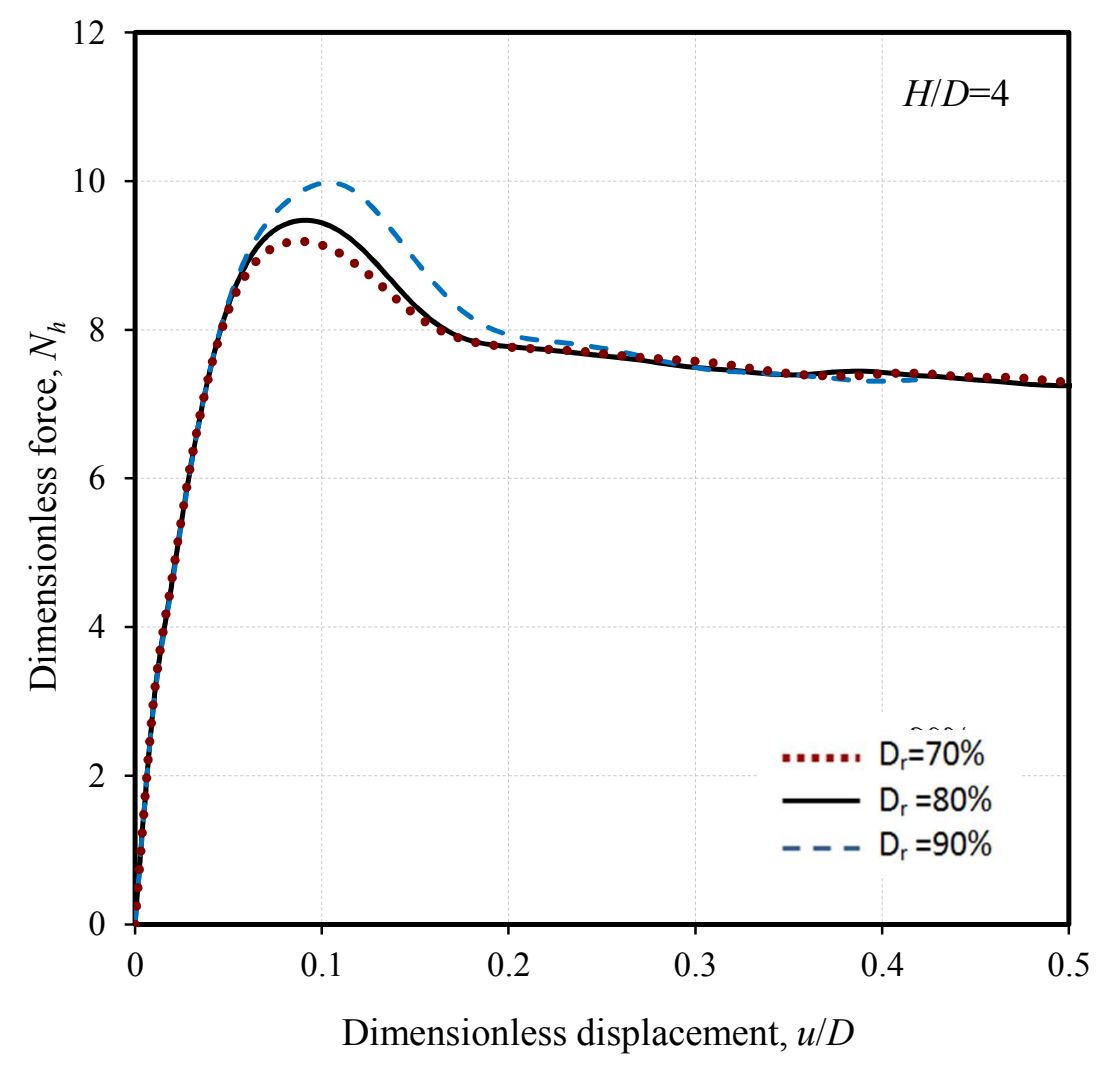

Fig. 17. Effect of relative density on dimensionless force $N_{h}$ for $H / D=4$ and $D=300 \mathrm{~mm}$ 
a) at $u / D=0.12$
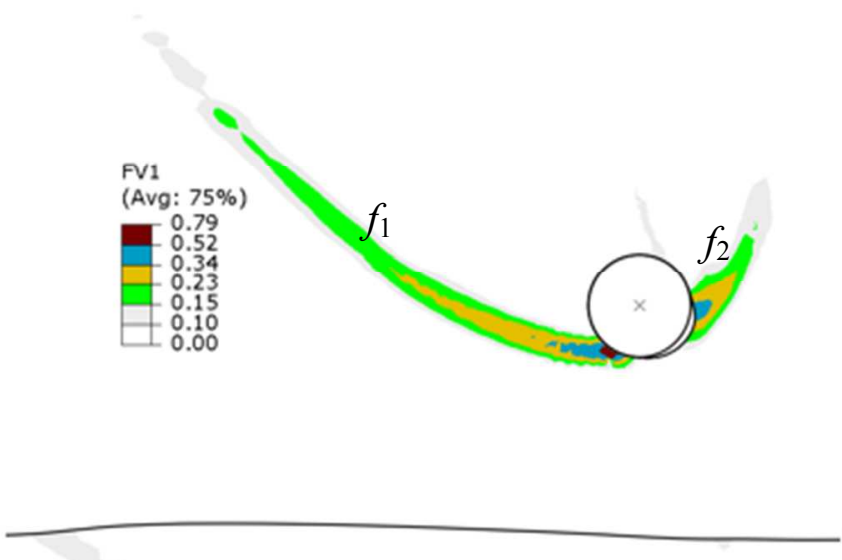

b) at $u / D=0.17$
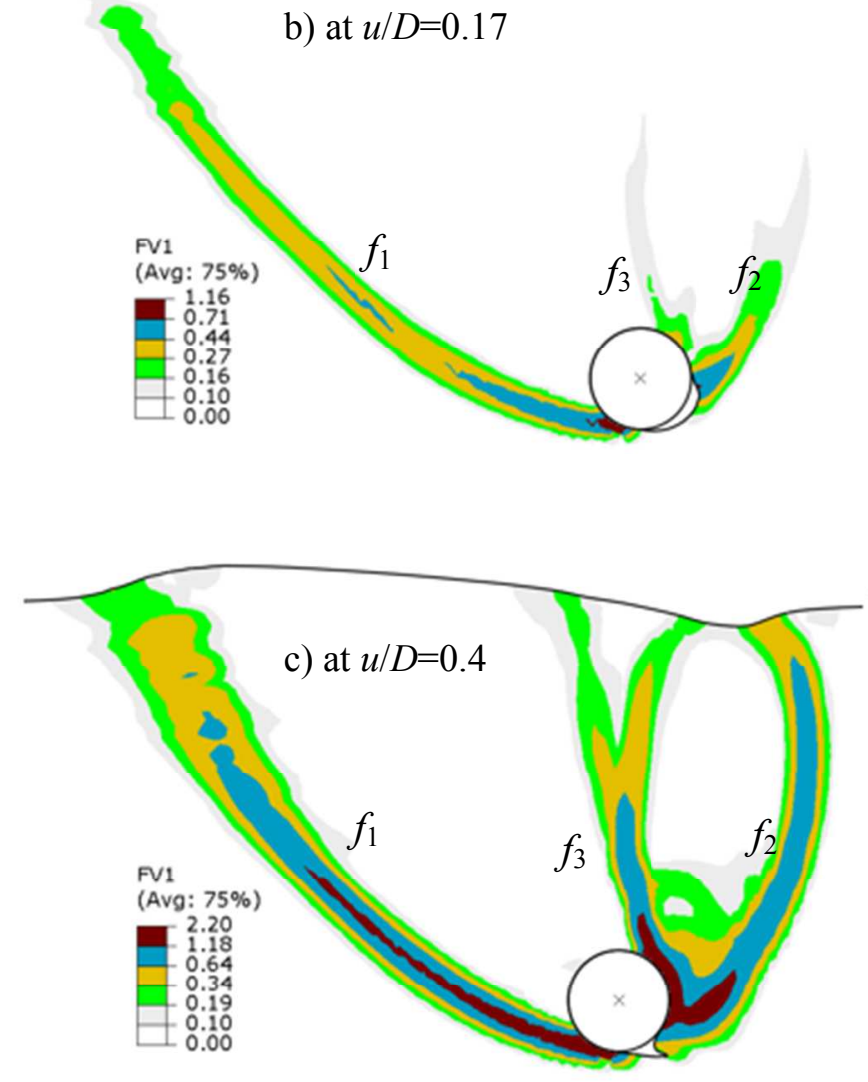

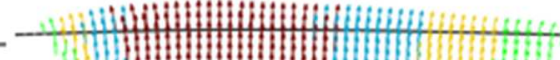

(d)
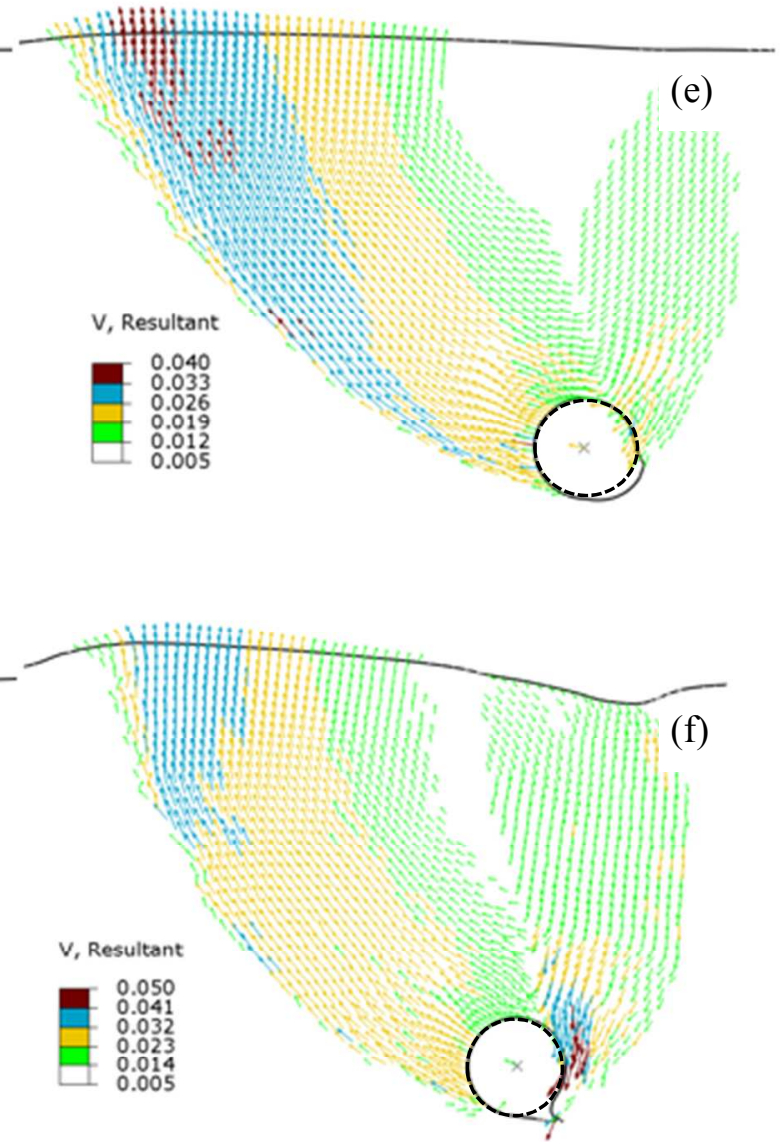

Fig. 18. Strain localization and instantaneous velocity vectors for $H / D=4$ and $D=300 \mathrm{~mm}$ 
(g) Model test (after Turner 2004)

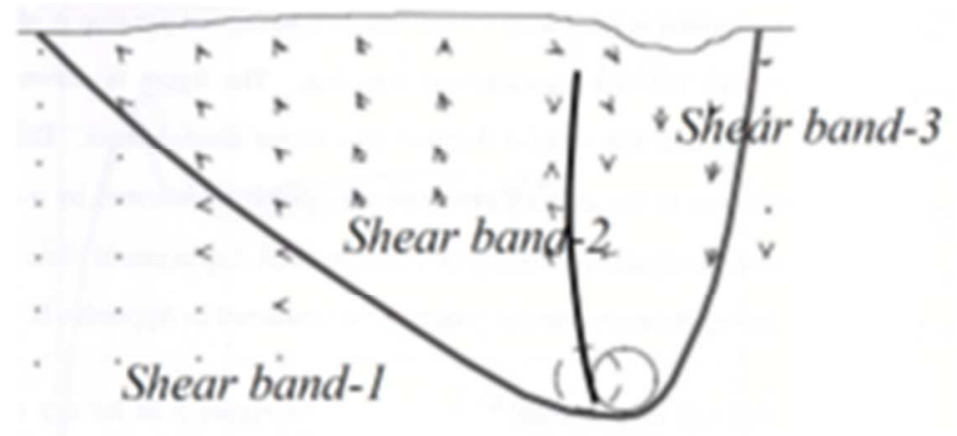

Fig. 18 (cont) 
FV1

(Avg: $75 \%$ )
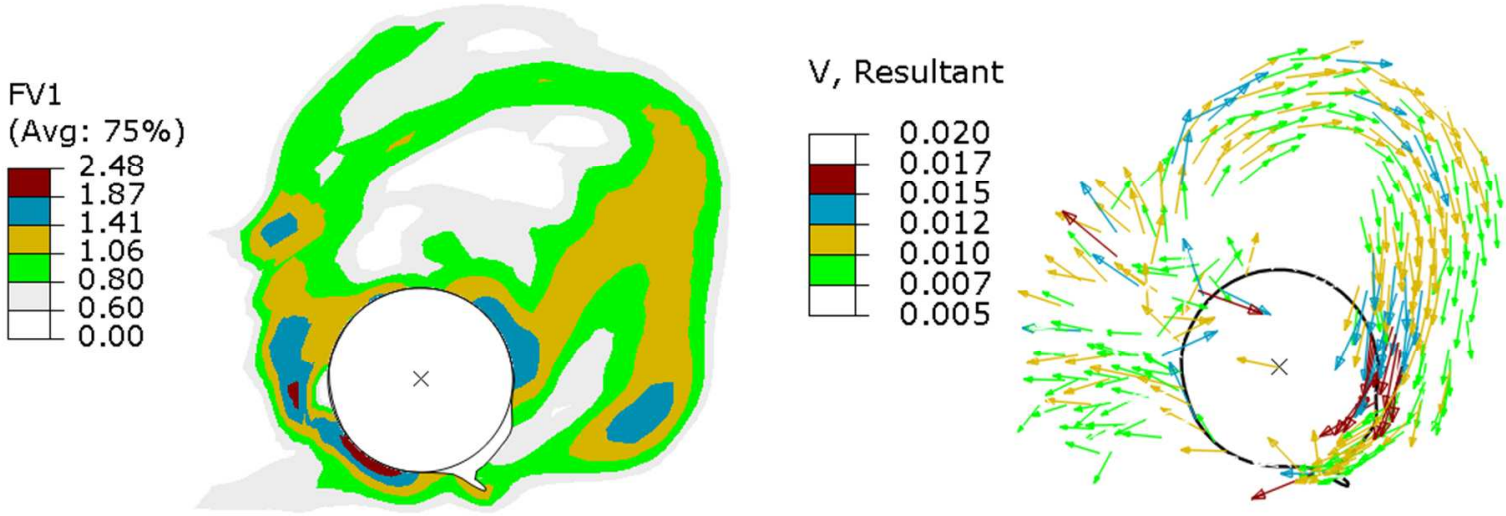

Fig. 19. Plastic shear strain and velocity vectors for $H / D=10$ and $D=300 \mathrm{~mm}$ at $u / D=0.72$ 
Table 1: Geometry and soil parameters used in the FE analyses

\begin{tabular}{|c|c|c|}
\hline Parameter & Triaxial test & Model test (Parametric Study) \\
\hline External diameter of pipe, $D(\mathrm{~mm})$ & - & $102(100,150,300)$ \\
\hline$K$ & 150 & 150 \\
\hline$n$ & 0.5 & 0.5 \\
\hline$p_{a}\left(\mathrm{kN} / \mathrm{m}^{2}\right)$ & 100 & 100 \\
\hline$v_{\text {soil }}$ & 0.2 & 0.2 \\
\hline$A_{\psi}$ & 3 & $5(3,3.8,5)$ \\
\hline$k_{\psi}$ & 0.5 & $0.8(0.6,0.7,0.8)$ \\
\hline$\phi_{\text {in }}^{\prime}$ & $29^{\circ}$ & $29^{\circ}$ \\
\hline$C_{1}$ & 0.22 & 0.22 \\
\hline$C_{2}$ & 0.11 & 0.11 \\
\hline$m$ & 0.25 & 0.25 \\
\hline Critical state friction angle, $\phi_{\mathrm{c}}^{\prime}$ & $31^{\circ}$ & $35^{\circ}$ \\
\hline Relative density, $D_{r}(\%)$ & $70,80,90,100$ & $80(70,80,90)$ \\
\hline Unit weight, $\gamma\left(\mathrm{kN} / \mathrm{m}^{3}\right)$ & - & $17.7(17.31,17.7,18.12)$ \\
\hline Interface friction coefficient, $\mu$ & - & 0.32 \\
\hline Depth of pipe, $H / D$ & - & $1.5 \& 5.5(2,4,6,10)$ \\
\hline
\end{tabular}

Note: Numbers in parenthesis in right column show the values used in the parametric study 
Fig. 1. Consolidated isotropically drained triaxial test results on dense sand (after Hsu and Liao 1998): (a) stress-strain behaviour (b) volume change behaviour

Fig. 2. Peak friction angle of crushed silica sand from triaxial and simple shear tests (after Ahmed 1973)

Fig. 3. Modeling of stress-strain behaviour of dense sand using modified Mohr-Coulomb (MMC) model (plane strain condition)

Fig. 4. Typical finite element mesh for $H / D=2$ and $D=300 \mathrm{~mm}$

Fig. 5. Comparison of FE and triaxial compression tests results $\left(\sigma_{\mathrm{c}}=39 \mathrm{kPa}, D_{r}=80 \%\right)$ : (a) stressstrain behaviour (b) volume change behaviour

Fig. 6. Effect of confining pressure on triaxial tests $\left(D_{r}=80 \%\right)$ : (a) stress-strain behaviour (b) volume change behaviour

Fig. 7. Effect of relative density: (a) stress-strain behaviour (b) volume change behaviour

Fig. 8. Comparison of FE results with the large scale test results (Trautmann, 1983)

Fig. 9. Location of shear band at $u / D=0.12$ : (a) using $\mathrm{MMC}$ (b) using $\mathrm{MC}$ and MMC model

Fig. 10. Shear band formation and strength mobilization for $H / D=5.5$ and $D=102 \mathrm{~mm}$ at $u / D=0.12$ with MMC model: (a) plastic shear strain $\gamma^{\mathrm{p}}$, (b) mobilized $\phi^{\prime}$, (c) mobilized $\psi$

Fig. 11. Effects of diameter on force-displacement curve for $H / D=6$

Fig. 12. Effect of pipe diameter on $N_{h}$ for $H=600 \mathrm{~mm}$ 
Fig.13. Effects of burial depth on $N_{h}$ for $D=300 \mathrm{~mm}$

Fig. 14. Comparison of peak resistance $N_{h p}$ with previous studies

Fig. 15. Effect of $A_{\psi}$ on dimensionless force $N_{h}$ for $D=300 \mathrm{~mm}$

Fig. 16. Effect of $k_{\psi}$ on dimensionless force $N_{h}$ for $H / D=4$ and $D=300 \mathrm{~mm}$

Fig. 17. Effect of relative density on dimensionless force $N_{h}$ for $H / D=4$ and $D=300 \mathrm{~mm}$

Fig. 18. Strain localization and instantaneous velocity vectors for $H / D=4$ and $D=300 \mathrm{~mm}$

Fig. 19. Plastic shear strain and velocity vectors for $H / D=10$ and $D=300 \mathrm{~mm}$ at $u / D=0.72$ 